\title{
Systematic Stock Market Characterisation and Development: Perspectives from Random Matrix Theory, Option Pricing, Genetics, and Global Economics
}

\author{
Patrick Oseloka Ezepue ${ }^{*}$, Thomas Chinwe Urama², Mahmoud A. Taib Omar ${ }^{3}$ \\ ${ }^{1}$ School of Statistics and Information Modelling, International Centre for Research and Enterprise Development, Sheffield, UK \\ ${ }^{2}$ Statistics and Information Modelling Research Group, Department of Engineering \& Mathematics, Sheffield Hallam University, \\ Sheffield, UK \\ ${ }^{3}$ Department of Mathematics, Faculty of Education, University of Sebha, Sebha, Libya \\ Email: ^patrick.ezepue@sky.com, thomas.c.urama@student.shu.ac.uk, maitab2@gmail.com
}

How to cite this paper: Ezepue, P.O., Urama, T.C. and Omar, M.A.T. (2019) Systematic Stock Market Characterisation and Development: Perspectives from Random Matrix Theory, Option Pricing, Genetics, and Global Economics. Journal of Mathematical Finance, 9, 105-151.

https://doi.org/10.4236/jmf.2019.92007

Received: September 27, 2018

Accepted: April 5, 2019

Published: April 8, 2019

Copyright $\odot 2019$ by author(s) and Scientific Research Publishing Inc. This work is licensed under the Creative Commons Attribution International License (CC BY 4.0).

http://creativecommons.org/licenses/by/4.0/

(c) (i) Open Access

\begin{abstract}
We explicate the need and pathways for systematic stock market characterisation and development (SSMCD) and the role of Random Matrix Theory (RMT) in SSMCD research. This is the first time SSMCD, itself a nascent area of empirical finance introduced by the first author, is linked to RMT. Our focus is on the Nigerian Stock Market, particularly using RMT techniques to correlate respective asset prices in the NSM. The resulting insights are combined with those from related works on stochastic-times series analyses of stylised facts and six main market issues typically explored in empirical finance (efficiency, bubbles, anomalies, volatility, valuation and predictability), to illustrate SSMCD pathways in the NSM. Specifically, the RMT analyses focus on the cross-correlation matrix $\mathrm{C}$ of the stock index returns in the Nigerian Stock Market (NSM) from the period 2009 to 2013. Within this purview, we test the eigenvalues of the selected assets from the NSM and use their respective eigenvectors and inverse participation ratios to determine the stocks that drive the market dynamics. A method of obtaining a realistic implied correlation matrix for a hypothetical portfolio of some given assets selected from those considered in the empirical correlation matrix of the assets is considered. The positive implied correlation matrix shows that the corresponding assets in the NSM move in the same direction, meaning that portfolio diversification is not an optimal investment strategy. Hence, investing on derivative assets like call and put options is recommended. Further SSMCD implications of the analyses are foreshadowed. Also, we develop the links among
\end{abstract}


SSMCD, macroeconomic modelling of national and global economic trends amid cycles of booms and crises. Highlights of an econome derived from analogies with sequencing and editing of genomes in molecular biology are provided.

\section{Keywords}

SSMCD, RMT, Cross-Correlations, Implied Volatility, Option Pricing, Macroeconomics, NSM, Genome, Econome

\section{Introduction}

In a three-part paper system, [1] examines the metaheuristics of the 2007-2009 global financial crises and their implications for modelling integrated financial systems, especially the Nigerian, African and other emerging economies. Parts I and II of the paper system periscope the connections among financial risk management, investment theory, portfolio theory and management (including constructs like utility functions, risk aversion, optimal complete portfolios among different asset classes), and the nature of advanced mathematical sciences, finance and economics research requisite for detecting such crises and managing their consequences for households (h), firms (f) and governments (g); see Figure 1. Part III of the paper system explores wider reaches of such advanced multidisciplinary research regarding financial globalisation, domestic monetary policy and their macroeconomic connections. This third part is a rejoinder to the inaugural professorial address by the then Governor of the Central Bank of Nigeria (CBN), Professor Charles Soludo, entitled: Financial Globalisation and Domestic Monetary Policy: Whither the Economics for the $21^{\text {st }}$ Century? The term "Systematic Stock Market Characterisation (SSMC)" was coined in [1] [2] regarding the nature of connectionist research which ties up the above ideas and charts a New Economics for the $21^{\text {st }}$ Century accordingly. It was recently elaborated in SSCMD to include an emphasis on using the characterisation results to develop financial markets and economies, the D strand of SSMCD [3].

Figure 1 illustrates the web of internal firm-level and external macroeconomic-level transactions by typical market participants, households (h), firms (f) and governments $(\mathrm{g})$, in a globalised financial market. It is against this overall picture of the interconnections in the global financial system that we refract the lessons drawn from the credit squeeze for, say, general topics in investment analysis, bank financial management, portfolio theory and management, integrated financial risk management, and advanced financial engineering ideas, including derivatives. The object of SSMCD research is to portray the theatrics of what could go wrong, what works, and how the lessons gained in the research and analysis of economic systems and financial crises apply to a new way of doing things. 


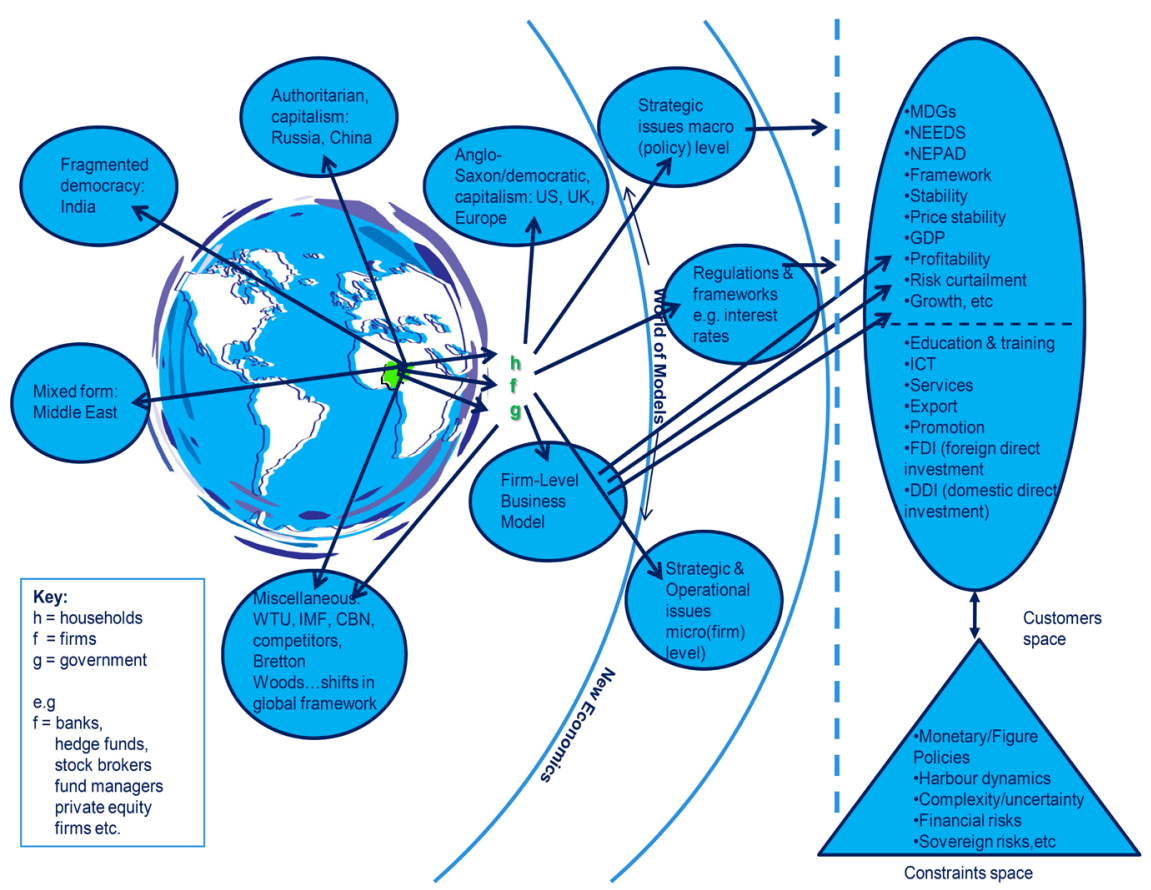

Figure 1. Policy Analysis and Decision Spaces for Economic Agents/Market Participants in a Globalized Financial World (adapted from [2], Figure 5, p. 218). (Legends: Policy Analysis goals in the big ellipse: Millennium Development Goals (MDGs, now replaced with 2030 UN Strategic Development Goals, SDGs); Nigerian Economic and Empowerment Development Strategy (NEEDS); Price Stability; Gross Domestic Policy (GDP); Firms' Profitability/Risk Curtailment; levels of Education and Training; ICT; Services; Export Promotion; Foreign Direct Investment (FDI); Domestic Direct Investment (DDI also linked to Fiscal Policy; The Constraints Space in the triangle includes. Monetary Policies; Labour Dynamics; Complexity/Uncertainty; Financial Markets and their microstructure; Sovereign Risks, etc.).

For a brief description of the elements of Figure 1, consider, for example, a Nigerian bank (f) whose relationships with the world are represented by indicated arrows. This bank is located in Nigeria as the innermost business environment, within which it considers its competitors as it trades the financial system. If it chooses to do business only in Nigeria, then it is a national bank. The next encasing business environment is the African continent and its various regions, for example the West African sub-region. Hence, the bank may expand to different regions in Africa as a regional or continental player. Imagine also that the bank has more aggressive ambitions as witnessed by both Zenith Bank and Access Bank opening offices in London. Then an arrow links the bank to the Anglo-Saxon democratic capitalism of US, UK and Europe as shown. We have also used indicative arrows to show how the bank may wish to associate itself with other regions of the world, with different brands of capitalism. Notice that we have expanded $f$ to capture other market participants with significant operations in most markets, for example hedge funds, stock brokers, fund managers, and private equity firms.

What is of interest is what these various levels of play portend for the way the 
entities are managed financially. This leads out arrows to the next important encasing world of relationships-the world of models. This world illustrates the fact that $\mathrm{f}$ must consider strategies that inform its overall approaches to doing business at the macro-economic (policy) level, models that ensure compliance with and fruitful exploitation of the regulatory frameworks, and finally operational models of how it does business at the firm-competition level. We give this a pride of place in the decision box labelled firm-level business models, within the first circle of relationships. It is with these different models/relationships in view that we conceive of a new way of doing business, which reckons with the lessons of the credit squeeze, the new economics or new analysis, depending on whether we are looking at the overall economy or the firm-industry level. Henceforth, we do not make this distinction and use the two terms interchangeably.

Within the inner constellation of its relationships with different economies, we also link $\mathrm{f}$ to other miscellaneous worlds, notably the World Trade Organization (WTO), African Development Bank Group (ADBG), the International Monetary Fund (IMF), World Bank and its affiliates, for example the International Finance Corporation (IFC), Sovereign Wealth Funds (SWFs) like those in China and Middle East. These entities may want to effect strategic alliances with $\mathrm{f}$ in order to access the Nigerian financial markets. Crucially, relationships between $\mathrm{f}$ and the world bodies is more of compliance with the international regulatory frameworks, but most usefully the unpacking of international research, debates and policies flowing from them with regards to their implication for smarter approaches to doing business. For example, every serious bank always scans the universe of world reports, trends, statistics and policy shifts, to maintain relevance and agility of its business models as shifts in global frameworks happen. Consider the fact that major financial players in developed markets are potentially interested in investing reasonable amounts of money in emerging markets. Any financial player $f$ through which these moves occur must, therefore, be technically ready to swim with these sophisticated players to its own well-considered advantage, and preferably to the mutual advantage of both players. There is no way this could reasonably be expected to be the case if $\mathrm{f}$ did not understand the complexity in design of and uses for effective risk management of derivatives and financial securitization. This is the reason professionals should be trained sufficiently deeply in the art and science of financial engineering.

The arrows finally point to a set of possible analysis goals that drive f's decision making (and that of other participants $\mathrm{h}$ and $\mathrm{g}$ ) as in the big ellipse, and possible constraints that affect the financial decisions from all these relationships, as in the triangle. For example, an $\mathrm{f}$ may aim to optimize business profitability, curtail attendant risks and generate healthy business growth simultaneously. It will have to do this with some available ICT power, sets of systems and processes (its enterprise engineering capabilities), the initial education and continuing professional development of its staff, and degrees of foreign direct in- 
vestment it allows. Similarly, a g will have to conduct its financial decisions and policies mindful of, say, the international benchmarks of national development it must attain, for example the 2030 UN Strategic Development Goals (SDGs) formerly known as Millennium Development Goals (MDGs), overall financial stability, price stability, increases in gross domestic product (GDP), and other macroeconomic indicators, as explored in part III of [1].

Constraints in financial decision making arise also for all participants such as constraints on overall monetary/fiscal policy of the types discussed in Professor Soludo's inaugural lecture and part III of [1], plus labour market dynamics and sovereign risks, particularly as affects the government ( $g$ ) in the figure. For firms, the main constraints to explore are the complexity and uncertainties of financial instruments and outlooks across the world, respectively in parts I and III of [1], whereas part II of [1] practically illustrate the ideas in financial (risk) analysis, investment and bank financial management. This paper explores some aspects of the nexus between financial derivatives and SSMCD.

Reiterating the need for a new economics in firm-level decision making, part I of [1] notes that there are far too many objectives and constraints which determine the analysis pathways in different decision making contexts, for an encapsulation within a limited set of arguments to be possible. Hence, what we can achieve in this paper is convey a flavour of the new thinking in selected contexts and examples, as earlier mentioned. In the subsection of part I of paper [1] entitled "The nature of new financial analyses at firm-level in light of the credit squeeze", we assert as follows:

Firms participating in financial markets must consider reasonable assumptions on the overall economy, the levels of key parameters (e.g. interest rates, inflation targets, etc.) and regulatory regimes in the detailed modelling they do. To take as much guess work out of these assumptions as possible, smart firms can mimic the way central policy making organs set these parameters within their own organizations. They can achieve this by literally "living in the minds of the policymakers" via near identical simulations of the future levels of the parameters. Very often the new analysis will be an amalgam of approaches in which macroeconomic parameters are inputs into the multiple objective functions which are optimized, to make the best feasible decisions. Importantly, the analyses must pass beyond mere complex modelling to realistic judgments of what steps to take in conditions of complexity and uncertainty-a typically heuristic analysis, therefore. The reality of the liquidity risk problems leading to the collapse of financial and other firms in the crisis necessitates that the new analysis adequately considers both earnings and corporate finance objectives. The effective consideration of such objectives requires a sense of depth in the manner of training offered to finance professionals through $\mathrm{MSc}, \mathrm{MBA}$ and $\mathrm{PhD}$ programmes-a depth that means they can weigh all key issues in problem solving within their organizations, particularly within SSMCD lenses. Finally, skills in constructing the sort of business models that bring all such key perspectives to- 
gether are required, for example a business model that smartly generates revenue and at the same time minimises the attendant risks of doing business.

[3] discusses "how different streams of mathematical and statistical finance research should be flexed into a DNA-deep mind-style systematic stock market characterisation and development (SSMCD) framework". This will help to develop some governing economic and investing principles which market participants-investment analysts, fund managers, economists, management of stock exchanges, banks and, say, monetary policy committees of the Central Bank of Nigeria-will use as guardrails in their investing and policy making decisions.

The subject of SSMCD was first formally introduced in [2]. The latter mapped the dynamics of the Nigerian Stock Market (NSM) at overall market level, by using the All Shares Index of the market to investigate six key market features studied in empirical finance (financial economics), namely market efficiency, bubbles, anomalies, volatility, valuations, and predictability. It was found, for example, that the NSM was weak-form inefficient and despite the wild shocks impacted on the market by the 2007-2009 global financial crisis, it did not manifest evidence of bubbles. These facts suggest the need to characterise the market at sectoral levels, for example, banking and financials, oil and gas, telecommunications, and agriculture.

The SSMCD work should link developments in those sectors to macroeconomic influences like inflation rates, consumer price index, interest rates, and exchange rates. The point is to characterise the NSM systematically across twelve key sectors into which the financial assets are divided, in a way that mimics gene sequencing and editing in biology. The effect is that, same as the genome facilitates the tracking of disease conditions and development of potential cures for them, investment strategies and policy making in the NSM would be improved through the econome and such events as financial crises better predicted, [4]. For an indication of sector categorisations in typical financial markets, we note the following Monday December 24, 2018 Times UK classification of business equity prices in the UK financial markets: banking and finance; investment companies; consumer goods; construction and property; health; engineering; industrials; leisure; natural resources (commodities); professional and support services; retailing; technology; telecoms; transport; technology; and utilities. These 16 sub-sectors of the UK economy can be subjected to detailed SSMCD analyses which can be pieced together to reveal the character of UK SSMCD econome. Similarly, the Nigerian financial system is composed of 189 companies in equities, 2 listed Exchange Traded Funds, and 55 listed bond (fixed-income) instruments; these are not listed here to save space, see [5], p.15. Hence, SSMCD work entails characterising equity, bonds, commodity, and real estate assets and sectors in an economy, including hybrid markets, with the goal of constructing early warning dashboards that capture the causal and interpretational dynamics of market movements, augmented by event histories of central bank regulatory, financial and banking reforms, as well as crises. 
We note that an SSMCD-based econome is not expected to have all the attributes of a DNA sequence associated with, say, the human genome. Given the radical uncertainty in the economy, whilst protein coding via biological DNAs is "generally deterministic", the envisaged SSMCD econome is a non-deterministic analogy of biological DNAs. It is a mechanism for sense-making in the economy and for predicting likely trends in the macroeconomy. The results will therefore be dynamically adjusted across different economic experiences and events, in qualitatively as well as quantitatively data-driven ways. Furthermore, using the SSMCD econome in finance and economics is expected to correct for specific deficiencies of different analytical approaches such as the bad out-of-sample performance of RMT results noted by one of the reviewers to this paper. This is because SSMCD results triangulate different approaches to financial and economic analysis as explained around Table 1 in this paper.

Following [2], additional research within the Statistics, Information Modelling and Financial Mathematics Research Group at Sheffield Hallam University, UK, was conducted on share prices and returns of Nigerian banks [6]. The results manifest evidence of bubbles in the banking sector, which were masked at the overall level in [2]. This paper emanates from complementary work on derivatives and is based on Random Matrix Theory (RMT), which uses cross-correlations among equity returns in the NSM to assay the dynamics of the market and isolate the driving forces and stocks, amongst other objectives. Whilst the RMT results inform the pricing of options and stated NSM policy on deepening the market through derivatives trading, they also support SSMCD research in ways discussed in [7] and this paper. Again, [3] is the most recent work that develops SSMCD thinking in more detail than previous studies.

We acknowledge the view from one of the reviewers of this paper that "there is a trend in economic and financial research that systematically summarizes financial conditions and then uses them to do forecasts", hence, the need to distinguish SSMCD from such other approaches. First, SSMCD is not positioned as completely distinct from mainstream economic and financial forecasting approaches. As shown in the literature and the explanatory notes to Table 1, it is an integrative approach which argues that information from different economic modelling techniques should be combined in specified contexts (for example the economic management of firms in different sectors of an economy and national governments), in such a way as to generate a systematic characterization of the market sectors, overall stock and capital markets, and wider macroeconomy of a country. The logic of the systematic stock market characterization and development (SSMCD), then is to have a deeper assay of the cause-effect and other meaningful correlations among economic phenomena that engender changes in an economy and its different sectors.

The above thinking is akin to realizing, to some extent, an econome that plays the same role in economics and finance as the genome plays in applied and molecular biology. In effect, SSMCD warrants a more pervasive characterization of different economic sectors (for example subsectors of a stock market) than is 
Table 1. Application/professional scope of financial mathematics.

\begin{tabular}{lll}
\hline - Asset/Liability Management & • Liquidity Modeling & • Risk Governance \\
- Alternative Investments & • Market Risk Modeling & • Securitization \\
- Behavioural Finance & • Risk Management & • Valuation \\
- Capital Budgeting & • Modeling Techniques and & • Time Series Modelling \\
- Credit Risk Modelling & Tools & • Data Analysis \\
- Econometrics & • Operational Risk & • Trading Systems \\
- Board Governance & • Portfolio Construction & • Market Microstructure \\
- High Frequency Trading & • Quantitative Trading & • Interest Rate Modeling \\
- Legal & (Buy-side) & • Management Technology \\
- Regulatory & • Quantitative Trading (Sell-side)
\end{tabular}

Source: Adapted from www.iaqf.org (2014).

currently implemented in the literature regarding particular economic motives such as investments, risk management, international private equity, derivatives trading, hedge fund management, and even central banking. This paper, therefore, identifies pathways for achieving such systematic characterization, including: 1) analyses of six key empirical finance issues that underpin market movements (efficiency, bubbles, anomalies, volatility, predictability and valuation), augmented by stylized facts of asset prices and returns in different market sectors; 2 ) better choice of macroeconomic analysis variables that are potentially more predictive of economic trends and consideration of more insightful questions and issues that underpin such [8] [9]; and 3) extension of identified good practices in the systematization of the analyses such as epitomized in [4] [10] and a plethora of algorithmic trading platforms used by investment banks and other asset management firms; and 4) the role of RMT in linking financial derivatives to SSMCD work.

To achieve such SSMCD objectives, which accommodate the above range of (short-, medium- to long-term) analyses and forecasting, requires an army of academics, graduate students, economics and finance professionals. As argued in the above references and the paper, given the radical uncertainty of the economy, emphasis should be placed more on understanding the complex interplay of forces that drive an economy, market sectors, and overall financial markets, to better manage economic outcomes, than on forecasting future states of the economy, since forecasts are rarely that accurate. The aim is to have an early warning system that predicts significant changes such as financial crises as evidenced by Dalio's ability to predict the 2007-2009 global financial crisis.

Indeed, a key contribution of this paper to knowledge is the identification of the above-mentioned pathways for extending existing work in this area, which is in effect a purposeful synthesis of the arguments in the supporting references into a system of checklists that constitute an econome. This is still work in progress. Furthermore (that is, additional to the potential extension of the systematic characterization of financial markets in [4] and [10]), the contributions to knowledge from this paper consist in: 1) an elucidation of the nexus among RMT results, macroeconomic and SSMCD insights (section 4 of the paper), in- 
cluding the concatenation of analytical techniques involved; 2) an explication of the labyrinths of intelligent questioning, issues and predictive variates within this nexus, as elucidated in [8] [9] [10], for example, particularly the manner in which these elements engender connected knowledge of the cause-effect relationships which drive market volatility and crises in an economy; 3 ) in light of these remarks, the elucidation, for the first time known to us in the literature, of the nature of SSMCD-based systemics and econome which glue all the ideas together (section 6 of the paper); 4) similarly, the nature of new and experimental economics that flow from these ideas, linked to potential SSMCD innovations in investment business models, capital and global economic management, and exemplified by ICRED's School of Global Economics with accompanying spin-offs and research centres (www.oseluxworldhero3e.com); 5) an indication of the constellation of collaborative research structures which support pervasive SSMCD research and enterprise development work entailed by the school at market, sector, national macroeconomic, continental (e.g. African) and global economic levels; and 6) in sum, a deep articulation of these contributions to

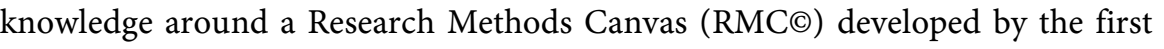
author and used to supervise SSMCD-focused PhD research topics (see Figure 2 in the concluding part of the paper).

It is noted in the paper, therefore, that SSMCD systemics connect contributing perspectives in Figure 1, Table 1, the gamut of literature in section 2 of the paper, and the ICRED Schools of Global Economics and Business, say, which underpin the design of integrated trading platforms such as those used by investment banks, investment and fund management firms, and central banks. The paper further argues the pedagogical merits of using insights from SSMCD thinking to deepen the teaching of finance, economics and their mathematical sciences underpinnings, such that academics, students and collaborating partners learn the art-science of successful global economics theorizing and real-world applications, to an extent that is currently lacking in traditional finance and economics departments in universities, especially those in developing countries.

We are, in these lights, strongly persuaded that the ideas in this paper talk to ICRED innovations in research, teaching, learning, assessments, consulting and community services, which are hallmarks of ICRED research-teaching excellence

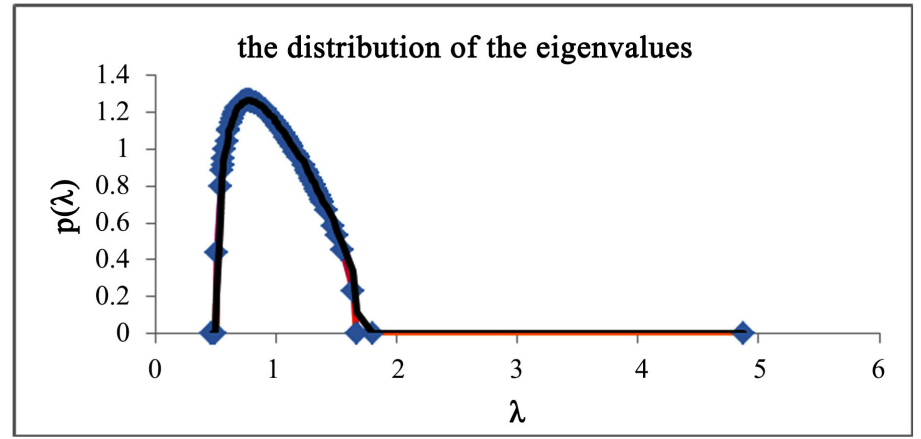

Figure 2. Theoretical (Marcenko-Pastur) empirical eigenvalues for NSM. 
in higher education and should therefore permeate universities across the world. For more related ideas see summary notes in the ICRED Schools of Innovation and Creativity, 7E Education and Enterprise Development, Statistics and Information Modelling, Advanced Multidisciplinary Studies (which includes Mathematical Sciences, Futurology and Complexity Systems), Global Economics, Global Business, and related $\mathrm{PhD}$ Research programmes at www.oseluxworldhero3e.com.

The rest of the paper is organised as follows. Section 2 summarises the key SSMCD ideas in previous studies. Section 3 presents RMT results. Section 4 discusses how the RMT results inform SSMCD, macroeconomic modelling, national and global economic management. Section 5 reiterates the nexus among SSMCD, macroeconomic modelling, global economic trends and genome-informed econome. Section 6 concludes the paper.

\section{Tenets of SSMCD Research}

It is argued in [3] that academics typically "research economic and finance themes within specialist silos, without sufficient integration among the fields of specialisation and strong focus on applying" combined insights on identified challenges in research, theory, practice, and policy-making. The key questions in SSMCD are: how do we systematise salient knowledge of empirical finance (based on the six key market issues mentioned above, traditional and algorithmic trading, portfolio management, investment analysis, macroeconomic modelling and monetary policy research, at overall and sectoral market levels), into "working frameworks and rules of thumb, for intelligently managing the 'gorgeous perpetual motion machine' [4] which describes the complexly uncertain (daily, monthly, annual, and yearly) fluctuations in the stock markets? In doing so, how do we balance out the see-saw of risk and returns across portfolios of asset classes, to continually create wealth?" How does the SSMCD econome (akin to the genome in modern biology) help us to automate such working frameworks and rules of thumb and improve economic and investment decision-making, at overall and sectorial levels of the market? How, therefore, can we resolve conflicts among the views of investment analysts, regulatory bodies, and policy makers in an economy (for example management of the Nigerian Stock Exchange and the Central Bank of Nigeria) regarding economic realities, conflicts that are due to improper forecasting of financial crises or the effects of economic policies on financial markets?

[4] and [10] systematically characterise financial market behaviours across different economic cycles, including historical analyses of contingent factors associated with different global or regional financial crises, and accurately predicted the 2007-2009 global financial crisis. The resulting investment algorithms enabled the investment firm, Bridgewater Associates, to become ultra-successful for several decades. The logic of SSMCD is that similar characterisations can be more formally implemented on the bases of different strands 
of analyses conducted on myriad classes of financial assets-equities, commodities, fixed-income assets (pensions, for example), currencies, real estate and derivatives.

[11] in [12] "examines the nature of multidisciplinary stochastic-time series and control engineering" underpinnings of SSMCD, financial policy and macroeconomic management, linked to ARCH-GARCH volatility modelling of the NSM All Shares Index for 2000-2010. Stochastic processes and modelling encompass a wide range of time-dependent probabilistic systems, including time series, Markov chains and processes, Poisson processes, Brownian motion and associated Levy processes, martingales, and derivative pricing models. Hence, SSMCD research collates findings on financial assets using different statistical, mathematical, economic, computing, financial engineering and econophysics tools and techniques. Those findings are used to characterise the behaviour of financial markets analogically similar to the sequencing and editing of genetic codes of humans and animals as well as weather forecasting.

\section{Strategic importance of SSMCD research}

As noted above, SSMCD research combines tools from different fields, for example stochastic-time series, control engineering models, artificial intelligence and algorithmic trading [3] [10], to more richly explore the time-varying dynamics of key features of stock markets, at overall and submarket levels. For example, in the NSM, we aim to characterise the overall market as well as key submarkets such as banking and financial services, telecommunications, energy, agriculture, and manufacturing sectors. Doing this across time epochs that accommodate different government policies and global financial crises reveals the effects of the policies and crises on stock market development and performance [2].

Six key market features which capture different aspects of market behaviour are efficiency, predictability, valuation, bubbles, anomalies, and volatility. These market features are to some extent linked with the fundamental concept of market efficiency. Market efficiency simply looks at how effective the market is in transmitting market information transparently and speedily to all market participants, to determine correct prices of market assets and thereby enable sensible valuation of the assets and related investment strategies, within the space allowed by overarching financial and macroeconomic (monetary and fiscal) policies [2]. Bubbles, anomalies and volatility collectively deal with abnormal movements in market data, for example interest rates, asset prices and returns, and market indices, which may be traceable to policy and economic factors such as 2004 bank reforms in Nigeria and the 2007 global financial crisis.

The gist of multidisciplinary research into stochastic-time series models associated with these market characteristics is that new results on the model structures are obtained, especially results that relate the emerging market dynamics to SSMCD, investing and economic policy making. Some candidate time series topics of interest in SSMCD research programme are autoregressive (AR), moving average (MA), mixed autoregressive-moving average (ARMA), autoregres- 
sive integrated moving average (ARIMA) models, vector autoregressive (VAR) and vector error correction (VEC) models which simultaneously model the effects of different economic variables on each other, and other specialised models such as (Generalized) Autoregressive Conditional Heteroscedastic (ARCH/ GARCH) models typically used to model volatility of financial data [2]. The strategic importance of SSMCD research has been emphasised in the above references and summarised in Figure 1.

The above notes reinforce the need to more robustly characterise stock markets considering the six key market issues and market data on interest rates, exchange rates, share prices, price/earnings ratios, inflation indices, consumer price indices, asset returns and indices, domestic and foreign investments, national economic growth, capital market dynamics, capital formation, and other macroeconomic indicators. The SSMCD research agenda also encompasses fundamental analyses of firm performances, meta-analyses of empirical finance studies on concerned economies, and their implications for national economic development, competitiveness, profitability, portfolio management of investment assets, and stock market development measured by market capitalization, value of traded securities, stock market liquidity issues. [2] and [3] discuss how GARCH modelling of the All Shares Index of the Nigerian Stock Market (NSM) informs SSMCD of the NSM. This paper looks at the derivatives pricing and RMT perspectives.

Papers published in [12] potentially contribute to SSMCD research the following approaches: simulation of asset prices in the NSM; Markov chain prediction of asset prices for a Nigerian bank, which is a facet of sector-based NSM dynamics that hints on the design of SSMCD-based trading algorithms; sector-based examination of bubbles; hints on building an SSMCD-based framework that exploits knowledge of the energy sector of the NSM; and a Mellin-transform approach to valuing European options which reiterates the merits and computational schemas for using derivatives to inoculate investment portfolios against different types of risks (currency, market, and interest rate risks, for example). We reiterate that SSMCD has levels-overall market level which will be of interest to NSM management and economic policy makers like the Central Bank of Nigeria (CBN) and the Ministry of Finance, and sector-based level which will interest market investors more.

The authors [13] present a paper in [12] on the "impact of contemporary technological tools on financial mathematics and financial management services". Table 1 from the paper captures the key areas of financial mathematics where such computing technologies are germane.

The main quest in SSMCD is precisely the use of computing technologies to automate investment decision-making in those areas of financial mathematics, in a way, also argued in the paper, "that connects Basic Financial Mathematics (BFM), Applied Financial Mathematics (AFM) and Financial Computational Technology (FCT), for the benefit of direct users, financial institutions, financial market analysts, indirect or proxy users, and learning community (academics, 
students, and professionals)". Table 1 shows some of the specific areas of work in global economics in which SSMCD work will be implemented or techniques of which contribute to SSMCD. For example, SSMCD thinking will be enriched by advanced research and applications of resulting findings in Asset/Liability Management, Alternative Investments, Behavioural Finance, Credit Risk Modelling, High Frequency Trading, Liquidity Modelling, Portfolio Construction, Quantitative Trading (buy- and sell-sides), Risk and Performance Attribution, Securitization, Valuation, construction of Trading Systems, deeper understanding of Market Microstructure, and Interest Rate Modelling.

Securitization particularly requires SSMCD-like maps of the behavior of asset prices. The construction of (algorithmic) trading systems is profoundly connected to SSMCD tenets such as applied in [3] and [10]). Some other items in the table remind us of applicable analytical techniques in SSMCD work such as Econometrics, Modeling Techniques and Tools, Time Series Modelling (also mentioned in this paper), Data Analysis techniques (RMT and other statistical methods), and Interest Rate Modelling. The table also shows areas of financial and economic policy making which a deeper SSMCD-based system could perhaps facilitate more than conventional approaches. These include Regulatory aspects (Financial Regulation, central bank economic management, bank and financial reforms), Risk Governance, and results-oriented Board Governance and Management Technology (including decision making dashboards).

It is our view that almost all finance and economics research works can be refracted on SSMCD lenses, contributing to its efficacy just as individual households and firms add extra energy generated from installed solar panels to national grids. Hence, the SSMCD consciousness is analogical to a national grid of analytical insights in the above areas of work in Table 1, complemented by the those in the School of Global Economics at the International Centre for Research and Enterprise Development (ICRED), www.oseluxworldhero3e.com. We will therefore enunciate PhD-level research topics on the nexus among SSMCD and the indicated areas, including first a baseline exploration of current knowledge in the areas, and second additional work that manifests new techniques and their linkages to specific SSMCD goals.

In the School of Global Economics and Capital Management of the International Centre for Research and Enterprise Development (ICRED), we conduct deep $\mathrm{PhD}$-level theoretical and applied economics research, to provide robust evidence base for effective decision-making under conditions of uncertainty and complexity [3] [4]. This is hinged on broad and deep characterisations of key sectors of an economy to elicit fundamental and contingent predictors of value in the sectors and the wider economy. Such SSMCD research links the stylised facts of a financial market and the six key empirical market features to macroeconomic factors like interest rates, inflation, consumption, investments, growth, and unemployment. Mapping the DNA of the overall financial market and key sectors this way (energy, banking and finance, health, telecommunica- 
tions, retail, and industrials, for example), combines with related techniques in applied statistics, financial mathematics, investing, applied economics, computational modelling, and business analytics, to produce a multiple-lensed view of economic and investing phenomena.

[4] and [10] offer practical ways to implement the SSMCD ideas explored in this paper. The principles for automating investment decision-making in Bridgewater Associates, compared to their expert but manual judgements, are the focus of the texts. Though Dalio and team do not use the SSMCD acronym in the texts, it is clear to us that they posit a good way to implement such a systematic framework. This suggests remarkably interesting research directions for combining SSMCD and Dalio's Principles in the above-mentioned Global Economics programmes. In doing this, just as Dalio was heavily consulted by policy makers in the US Federal Reserve and other parts of the world, because he used the system to correctly predict the 2007-09 global financial crisis, we should explore understandings of Nigerian central bank staff, those in other banks and financial institutions, investors and economic policy makers, and global financial institutions, in different aspects of the SSMCD research being implemented in ICRED and partner universities.

For this, we will use insights from [8]'s The End of Alchemy. Money, Banking and the Future of the Global Economy, [14]'s The Age of Turbulence with a New Chapter on the Credit Crisis, and [9]'s The Rise and Fall of Nations. Ten Rules of Change in the Post-Crisis World. For additional perspectives on the nature of (super)forecasting methodologies which could augment [4]'s Principles, see [15] and [16]. For complementary investment perspectives by successful investors and researchers, we recommend also a critical review of [17] and [18].

\section{Random Matrix Theory, Options Pricing and SSMCD}

In this section we excerpt key ideas in [19] and [20]) and related papers, to help us make sense of how RMT and derivatives pricing fit into SSMCD research remits. We focus on key insights in the papers. RMT investigates the spectral properties of the correlation matrix of asset prices in a stock market like the NSM. This helps to explore the dynamics of stock price movements in the NSM. The correlation matrix analysis compares the empirical correlation matrix with the Wishart random matrix. We reiterate that methodologically this paper is not a new empirical paper. It is rather a meta-analysis of disparate works by the authors and those in the references which shed meaningful perspectives on SSMCD. To minimize space in the paper, therefore, readers are referred to those references, especially [19] and [20] which describe the data on RMT aspects of the paper.

Correlation matrices of financial returns play a crucial role in various aspects of modern finance including investment theory, capital allocation, and risk management [21]. Investment analysts emphasise the ability of the models to support investment portfolios and risk management procedures required in the 
financial industry. Financial institutions usually construct investment portfolios that may include basket of derivatives and other trading products which depend largely on the correlation coefficients between underlying assets [22]. Authors [23] assert that high correlation reduces the benefits of portfolio diversification. In this respect, investors need to use derivative (for example option) trades to risk-manage their investment portfolios. Thus, it is of utmost importance to investors to comprehensively analyse the correlations among stocks in a stock market and relate them to risk-mitigating and return-maximising derivative trades.

Following the introduction of RMT into financial markets by [24], [25] and [26], it has been used to study the statistical properties of cross-correlations among financial assets and markets. Author [25] notes that the probability of large losses for a certain portfolio or option book is dominated by correlated moves of its different components, and a position which is simultaneously long in stocks and short in bonds will be risky as stocks and bonds usually move in opposite directions during crisis periods. Similarly, "for investors using derivatives products as a hedge on the underlying assets and for risk management, it is advisable that such investors should buy call and put options respectively for assets whose returns move in opposing directions as may be witnessed from the calculated empirical correlation matrix" [20], [26] and [27].

Investors need to understand how (implied) volatility, being a measure of market fluctuations, affects the dynamics of the market or vice versa. Hence, it is important to explore the relationship between market volatility and the coupling of stocks with one another using correlation matrices [19]. Correlations amongst asset volatilities are very useful for portfolio selection, options pricing and certain multivariate econometric models for price forecasting and volatility estimations [28]. It is known from these references that with regards to Black-Scholes option pricing model [29], the portfolio variance, $\rho$, of options exposed to Vega risk only is given by

$$
\operatorname{Var}(\rho)=\sum_{i, j, k, l} \frac{w_{i} w_{l} \Lambda_{i j} \Lambda_{l k} C_{j k}}{v_{j} v_{k} \sigma_{j} \sigma_{k}}
$$

where $w_{i}$ are the weights in the portfolio, $C_{i j}$ is the correlation matrix for the implied volatility for the underlying assets and the vega matric $\Lambda_{i j}$ is defined as

$$
\Lambda_{i j}=\frac{\partial p_{i}}{\partial v_{j}}
$$

with $p_{i}$ as the price of option $i, v_{j}$ is the implied volatility of asset underlying option $j$ and $\sigma_{i}$ is the standard deviation of the implied volatility $v_{i}$.

Similarly, it is noted in [30] that given a portfolio of $N$ assets, the portfolio variance $\sigma_{\text {port }}^{2}$ can be calculated using the formula

$$
\sigma_{\text {port }}^{2}=\sum_{i=1}^{N} \sum_{j=1}^{N} C_{i j} w_{i} w_{j} \sigma_{i} \sigma_{j}
$$

with $\sigma_{\text {port }}=$ annual standard deviation or volatility of the portfolio, $\sigma_{i}, \sigma_{j}=$ 
annual standard deviation or volatility of the asset $i$ and $j, w_{i}, w_{j}=$ weights of asset $i$ and $j$ respectively, and $C_{i j}=$ Correlation coefficient between asset $i$ and $j$ with $C_{i j}=1$ for $i=j, 1 \leq i \leq N$. Equation (3) can, therefore, be used in portfolio management. A portfolio that has minimum variance is said to be less risky. In our study, this can be illustrated by assigning some weight to a portfolio consisting of some selected stocks from NSM and then the value of $C_{i j}$ picked from the empirical correlation matrix coefficient of the respective stocks to determine better portfolio choice(s). The variances of the respective assets are as reflected in Equation (8) below. Authors [31] propose a proxy for calculating average correlation using only individual stock volatilities and that of the portfolio/index, starting from the definition of a portfolio variance given by:

$$
\sigma^{2}=\sum_{i=1}^{N} w_{i}^{2} \sigma_{i}^{2}+2 \sum_{i=1}^{N} \sum_{j>1}^{N} C_{i j} w_{i} w_{j} \sigma_{i} \sigma_{j}
$$

We recall that the Black-Scholes option pricing model [29] is subject to the assumption of constant volatility. Empirical evidence of implied volatility surface smiles and skews, as opposed to a flat surface expected from the model, shows that this assumption in untenable. Hence, implied volatility is best represented in options pricing as a parameter that varies with respect to time to maturity, moneyness or strike price of the option [29]. In the Black-Scholes option pricing model, historical stock price data is used to estimate this volatility parameter which can be plugged into the model to derive the option values. $\mathrm{Al}-$ ternatively, one may observe the market price of the option and invert the option-pricing formula to determine the volatility implied by the option price. This market assessment of an underlying asset's volatility as reflected in the option price is called implied volatility of the option [32]. Hence, the study of implied volatility and its relation to correlation matrix becomes indispensable in risk management and portfolio optimization.

[33] asserts that random matrix theory facilitates comparisons between the cross-correlation matrices obtained from empirical time series data for a period $T$ with a random Wishart matrix $W$ of the same size with the empirical correlation matrix, to obtain some information about the market(s) which is useful for portfolio optimization and risk management. RMT predictions represent an average over all possible interactions between the constituents of an asset in a given market under consideration. Deviations between the predictions of RMT obtained from observed empirical correlation matrices and the Wishart matrix are used to identify non-random, system-specific properties of markets under consideration. Such deviations provide information about underlying interactions among financial assets in a market like the NSM. Put another way, we compare the cross-correlation coefficients of price fluctuations of stock $i$ and $j$ against a random matrix having the same symmetric properties as the empirical matrix. The RMT distinguishes the random and non-random parts of the cross-correlation matrix $C$ and the non-random parts of $C$ which deviates from RMT results provide information regarding the genuine collective behaviour of the concerned stocks and the entire market at large. 
Knowledge of the said correlation dynamics is important for portfolio risk quantification and is of scientific interest to researchers in economics and financial mathematics [34] and [35]. Historically, RMT's role in interpreting correlations among individual stock price changes in a financial market are analogous to the difficulties experienced by physicists in the fifties in explaining the spectra of complex nuclei due to the huge amounts of spectroscopic data on the energy levels that were available. Thus, Random Matrix Theory (RMT) was developed to take care of the statistics of energy levels of complex quantum systems [36] [37] [38]. Similarly, for a stock exchange, the nature of interactions among constituent stock are unknown, hence the need to adopt RMT in explicating the interactions among individual stocks in portfolio optimization and risk management. The estimation of risk and expected returns based on variance and expected returns in a given portfolio follows Markowitz's model [39]. For this, the period $T$ under consideration has to be relatively large enough relative to the number of stocks or assets to minimize the noise in the correlation matrix. Two sources of noise associated with the use of RMT this way in a given financial market include the noise from the period length $\mathrm{T}$ and the noise from the finiteness of the time series of historical returns itself which introduces estimation errors (noise) in the correlation matrix [19] [20].

Authors [40] observe that the effect of noise strongly depends on the ratio $=$ $\frac{N}{T}$, where $n$ is the number of stocks considered and $t$ the length of the available time series. They note that for the ratio $r=0.6$ and above, there is a pronounced effect of noise on the empirical analysis [25] [26] [41], and that for smaller value of $r$ ( $r=0.2$ or less) the error due to noise drops to an acceptable level. In this paper, we use the empirical data obtained from the NSM, $r=\frac{82}{1018}=0.08<0.2$, which is an acceptable value. The gist of RMT as noted in [20] is this: "if the eigenvalues of the empirical correlation matrix and that of the Wishart matrix lie in the same region without any significant deviations, then the stocks are said to be uncorrelated and therefore no information or deduction can be made about the nature of the market since it is the deviations of the eigenvalues of the correlation matrix from that of the Wishart matrix that carries information about the entire market". However, if there exists at least one eigenvalue lying outside the theoretical bound of the eigenvalues in the empirical correlation matrix obtained from stock market returns, then the deviating eigenvalue(s) carry information about the market.

\section{The NSM Data}

The data consist of daily closing prices of 82 stocks listed in the NSM from $3^{\text {rd }}$ August 2009 to $26^{\text {th }}$ August 2013, a total of 1019 daily closing returns after removing assets which are delisted, non-trading or partially traded in this study period. The selected financial assets are drawn from Agriculture, Oil and Gas, Real Estates/Construction, Consumer Goods and Services, Health care, ICT, Financial Services, Conglomerates, Industrial Goods, and Natural Resources sec- 
tors of the NSM. For the daily asset prices to be continuous and to minimize the effect of thin trading, we remove public holidays in the study period. To reduce noise in the analysis, market data for a given day without trading information are assumed to be the same with the previous day. Also, infrequently traded stocks in the study period are eliminated. Let $P_{i}(t)$ be the closing price on a given day $t$, for stock $i$ and define the natural logarithmic return of the index as

$$
r_{i}(t)=\ln \frac{P_{i}(t+1)}{P_{i}(t)}
$$

where $r_{i}(t)$ is the asset return in an exchange like the NSM or the Johannesburg Stock Exchange (JSE).

\section{Theoretical Background}

To compute volatility, we calculate the price changes of assets in a market over a one-day time scale $\Delta t$ and denote the price of asset $i$ at a time $t$ as $s_{i}(t)$ with corresponding price change or logarithmic returns $G_{i}(t)$ over time scale $\Delta t$ as

$$
G_{i}(t)=\ln \left[S_{i}(t+\Delta t)\right]-\ln \left[S_{i}(t)\right]
$$

We quantify the volatility in asset return as a local average of the absolute value of daily returns of indices in an appropriate time window of $T$ days as

$$
v=\frac{\sum_{t=1}^{T-1}\left|G_{i}(t)\right|}{T-1}
$$

To standardize the values obtained from Equation (6) above for all values of asset $i$, we normalize $G(i)_{t}$ as follows:

$$
g(i)_{t}=\frac{\prec G(i)_{t}-\left\langle G(i)_{t}\right\rangle}{\sigma_{i}}
$$

where $\sigma_{i}=\sqrt{\langle G(i)\rangle_{t}^{2}-\left\langle G(i)_{t}\right\rangle^{2}}$ and $\langle\ldots\rangle$ represents the average in the study period.

From real time series return data, we calculate the elements of an $N$ x $N$ correlation matrix $C$ as follows

$$
C_{i j}=\langle g(i) g(j)\rangle=\frac{\left\langle\left[G_{i}(t)-\left\langle G_{i}\right\rangle\right]\left[G_{j}(t)-\left\langle G_{j}\right\rangle\right]\right\rangle}{\sqrt{\left[\left\langle G_{i}^{2}\right\rangle-\left\langle G_{i}\right\rangle^{2}\right]\left[\left\langle G_{j}^{2}\right\rangle-\left\langle G_{j}\right\rangle^{2}\right]}}
$$

where $-1 \leq C_{i j} \leq 1$, with $C_{i j}=0$ means that there is no correlation, $C_{i j}=-1$ implies anti-correlation and $C_{i j}=1$ means perfect correlation, for the empirical correlation matrix obtained from the implied volatility surface.

\section{Eigenvalue spectrum of the correlation matrix}

We compare the properties of matric $C$ with those of a random matrix [26] [42] [43] [44] [45]. [46] shows that the empirical correlation matrix $C$ can be expressed as

$$
C=\frac{1}{L} G G^{\mathrm{T}}
$$


where $G$ is the normalized $N \times L$ matrix and $G^{\mathrm{T}}$ is the transpose of $G$. This empirical correlation will be compared with a random Wishart matrix $R$ given by:

$$
R=\frac{1}{L} A A^{\mathrm{T}}
$$

to classify the information and noise in the system [42] [44], where $A$ is an $N$ x $L$ matrix whose entries are independent identically distributed random variables that are normally distributed and have zero mean and unit variance.

To use RMT in portfolio optimization and (derivative) assets risk management, we refer to the universal properties of random matrices, which include 1) Wishart distribution eigenvalues from the correlation matrix, 2) Wigner surmises for eigenvalue spacing, 3) the distribution of eigenvector components of the corresponding eigenvalues, and 4) Inverse participation ratios for eigenvector components of the C matrix [38]. The references [47] [48] [49] and [33] note that for the limit as $N \rightarrow \infty$, and $L \rightarrow \infty$ with $Q=\frac{L}{N}(\geq 1)$ fixed, the probability distribution $P_{r m}(\lambda)$ of eigenvalues $\lambda$ of $R$ is given by

$$
P(\lambda)=\frac{Q}{2 \pi \sigma^{2}} \frac{\sqrt{\left(\lambda_{\max }-\lambda\right)\left(\lambda-\lambda_{\min }\right)}}{\lambda}
$$

for $\lambda$ such that $\lambda_{\min } \leq \lambda \leq \lambda_{\max }$, where $\sigma^{2}$ is the variance of the elements of $A$. Here $\sigma^{2}=1$ and $\lambda_{\min }$ and $\lambda_{\max }$ satisfy

$$
\lambda_{\max / \min }=\sigma^{2}\left(1+\frac{1}{Q} \mp 2 \sqrt{1 / Q}\right)
$$

The values of lambda from Equation (11) that satisfy (12) and (13) are called the Wishart spectrum of eigenvalues from the $C$ matrix and they determine the bounds of the theoretical eigenvalue distribution. When the eigenvalues of matrix $C$ lie beyond these bounds, they are said to deviate from the random matrix bounds and carry some useful information about the market [25]. The distribution of eigenvalues (surmise of eigenvalue) spacing was introduced as the required test for the case when there are no significant deviations of the empirical eigenvalue distribution from the random matrix prediction [28]. When the eigenvalues so obtained from the $C$ matrix do not deviate significantly from the predictions of RMT, we apply the so-called Wigner surmise for eigenvalue spacing, otherwise called Gaussian orthogonal ensemble [50] which is given by

$$
P(s)=\frac{s}{2 \pi} \exp \left(-\frac{s \pi^{2}}{4}\right),
$$

where $\left(\lambda_{i+1}-\lambda_{i}\right) / d$ and $d$ denotes the average of the differences $\lambda_{i+1}-\lambda_{i}$ as $i$ varies.

\section{Distribution of eigenvector components}

That low-lying eigenvalues are random can be further verified by studying the statistical structure of corresponding eigenvectors. The $j$ th component of the eigenvector corresponding to each eigenvalue $\lambda_{\alpha}$ will be denoted by $v_{\alpha, j}$ and 
then normalized such that $\sum_{j=1}^{N} v_{\alpha, j}^{2}=N$. Authors [26] state that if there is no information contained in the eigenvector $v_{\alpha, j}$, then one expects for a fixed $\alpha$, that the distribution of $u=v_{\alpha, j}$ (as $j$ is varied) is a maximum entropy distribution. This, therefore, yields the Porter-Thomas distribution in the theory of random matrices written as

$$
p(u)=\frac{1}{\sqrt{2 \pi}} \exp \left(-\frac{u^{2}}{2}\right)
$$

It is known that the eigenvector components $v_{\alpha, j}$ for $\alpha=1,2,3, \cdots, n$ of an eigenvector $v_{\alpha}$ are normally distributed with zero mean and unit variance [51]. The distribution (14) above is expected to fit well the histogram of the eigenvectors, except for those corresponding to the highest eigenvalues which lie beyond the theoretical value of $\lambda_{\max }$ [25].

\section{Inverse participation ratio}

To quantify the number of components that participate significantly in an eigenvector, we use the inverse participation ratio (IPR), which shows the degree of deviation of the distribution of eigenvectors from RMT results and distinguishes a reference eigenvector with approximately equal components from another with a small number of large components [52]. For each eigenvector $v_{a}$, [26] define the inverse participation ratio as

$$
I_{\alpha}=\sum_{j=1}^{N}\left(v_{\alpha}^{j}\right)^{4}
$$

where $N$ is the number of asset time series (the number of implied volatilities) considered, and hence the number of eigenvalue components, and $v_{\alpha}^{j}$ is the $j$-th component of the eigenvector $v_{\alpha}$. There are two limiting cases of $I_{\alpha}: 1$ ) if $v_{\alpha}$ has identical components, $v_{\alpha}(j)=\frac{1}{\sqrt{N}}$, then $I_{\alpha}=\frac{1}{N}$; and 2) if $v_{\alpha}$ has one element with $v_{\alpha}(j)=1$ and the remaining components are zero, then $I_{\alpha}=1$. Therefore, the IPR can be illustrated as the inverse of the number of elements of an eigenvector that are different from zero that contribute significantly to the value of the eigenvector. Authors [53] note that the expectation of the IPR is given by

$$
\left\langle I_{\alpha}\right\rangle=N \int_{-\infty}^{\infty}\left[v_{\alpha}(j)\right]^{4} \frac{1}{\sqrt{2 \pi N}} \exp \left(-\frac{\left[v_{\alpha}(j)\right]^{2}}{2 N}\right) \mathrm{d} v_{\alpha}(j)=\frac{3}{N}
$$

since the kurtosis for the distribution of eigenvector components is 3 .

\section{Algorithm for Calculating Realistic Implied Correlation Matrix, $R^{Q}$}

Authors [22] define a valid empirical nxn correlation matrix as a matrix with the following properties: 1) all diagonal entries must be one which is the case for the empirical correlation matrix obtained from the sample of NSM stocks considered in this paper; 2) non-diagonal entries of $C_{i j}$ are real numbers in the closed interval $-1 \leq C_{i j} \leq 1$; 3 ) the empirical correlation matrix is symmetric; and 4) the empirical correlation matrix must be positive (semi) definite to accommodate matrix decomposition for some desired purposes like Monte-Carlo 
simulation [65]. Also, when the matrix $C$ is not an identity matrix, as is the case with the matrix derived from the asset return distribution of stocks selected from NSM, the implied volatility of the portfolio $\sigma_{\text {port }}^{Q}$ is given by

$$
\left(\sigma_{\text {port }}^{Q}\right)^{2}=W * S^{Q} * C^{Q} * S^{Q} * W^{\prime}
$$

Similarly, if $\sigma_{\text {port }}^{Q}$ is the implied volatility of the portfolio obtained from $C^{P}$, then it can be described as

$$
\left(\sigma_{\text {port }}^{P}\right)^{2}=W * S^{Q} * C^{P} * S^{Q} * W^{\prime}
$$

where $W=\left[\begin{array}{lll}w_{1} & \cdots & w_{n}\end{array}\right]$ are the weights of the respective stocks in the portfolio;

$$
S^{Q}=\left[\begin{array}{ccc}
\sigma_{1}^{Q} & \cdots & 0 \\
\vdots & \ddots & \vdots \\
0 & \cdots & \sigma_{n}^{Q}
\end{array}\right] \text { is a diagonal matrix obtained from the implied stan- }
$$

dard deviation of the studied assets, and

$$
C^{Q}=\left[\begin{array}{ccccc}
1 & C_{2,1}^{Q} & \cdots & C_{n-1,1}^{Q} & C_{n, 1}^{Q} \\
\vdots & \vdots & \ddots & \vdots & \vdots \\
C_{n, 1}^{Q} & C_{n, 2}^{Q} & \cdots & C_{n-1, n}^{Q} & 1
\end{array}\right] \text { is the desired realistic implied correla- }
$$

tion matrix

$$
\begin{gathered}
\text { or }\left(\sigma_{\text {port }}^{Q}\right)^{2}=\sum_{i=1}^{N} \sum_{j=1}^{N} C_{i, j}^{Q} w_{i} w_{j} \sigma_{i}^{Q} \sigma_{j}^{Q} \\
\rightarrow\left(\sigma_{\text {port }}^{Q}\right)^{2}=\sum_{i=1}^{N} w_{i}^{2}\left(\sigma_{i}^{Q}\right)^{2}+2 \sum_{i=1}^{N} \sum_{j>1}^{N} C_{i, j}^{Q} w_{i} w_{j} \sigma_{i}^{Q} \sigma_{j}^{Q}
\end{gathered}
$$

To identify $N \times(N-1) / 2$ correlations that satisfy Equation (18a), Authors [30] propose the following parametric form for implied correlations:

$$
C^{Q}=C^{P}-\varphi *\left(I_{n \times n}-C^{P}\right)
$$

where, $C^{Q}$ is the expected correlation under the objective measure and $\varphi$ is the parameter to be identified.

By substituting Equation (20) into Equation (18) we obtain:

$$
\varphi=-\frac{\left(\sigma_{\text {port }}^{Q}\right)^{2}-W * S^{Q} * C^{P} * S^{Q} * W^{\prime}}{W S^{Q}\left(I_{n \times n}-C^{P}\right) S^{Q} W^{\prime}}
$$

and from Equations (18) and (19) is equivalent to:

$$
\varphi=\frac{\left(\sigma_{\text {port }}^{Q}\right)^{2}-\sum_{i=1}^{N} \sum_{j=1}^{N} C_{i, j}^{P} w_{i} w_{j} \sigma_{i}^{Q} \sigma_{j}^{Q}}{\sum_{i=1}^{N} \sum_{j=1}^{N} w_{i} w_{j} \sigma_{i}^{Q} \sigma_{j}^{Q}\left(I_{n \times n}-C^{P}\right)}
$$

[30] impose a restriction on the values $\varphi$ to be in the region $-1<\varphi \leq 0$ for it to satisfy the technical conditions on the correlation matrix which includes that all the correlation $C_{i, j}^{Q}$, do not exceed one and that the correlation matrix is positive definite. Consider the cases when $\varphi>0$ which occurs when $\sigma_{\text {port }}^{P}>\sigma_{\text {port }}^{Q}$, since $\left(I_{n \times n}-C^{P}\right) \geq 0$ and this could make the realistic correlation matrix $C^{Q}$ to be invalid when $\sigma_{\text {port }}^{P}<\sigma_{\text {port }}^{Q}$ [54] [55]. This author proposes a 
formula for valid correlation matrix that will take care of this shortcoming as stated below. Given any two valid correlation matrices $C$ and $D$ of dimensions $n \mathrm{x}$ $n$, there exists another valid correlation matrix $F$ of the same dimension such that

$$
F=w * C+(1-w) * D
$$

where $w$ is a real number in the closed interval $0 \leq w \leq 1$. Our decision on the equivalent upper or lower bound equicorrelation matrix $C$ to be used in obtaining a realistic implied correlation matrix, therefore, depends on the nature of the inequality between $\sigma_{\text {port }}^{P}$ and $\sigma_{\text {port }}^{Q}$. The corresponding equicorrelation matrices are represented by $U_{n \times n}$ for upper equicorrelation matrix and $L_{n \times n}$ matrix whose entries are $-\frac{1}{n-1}$ for $i \neq j$ and 1 for $i=j$ as the lower equicorrelation matrix. Replacing equation $F$ by $C^{Q}$ and $D$ by $C^{P}$ in (23) yields

$$
C^{Q}=C^{P}+w *\left(C-R^{P}\right)
$$

and from Equations (18) and (19) we shall have:

$$
w=\frac{\left(\sigma_{\text {port }}^{Q}\right)^{2}-\left(\sigma_{\text {port }}^{P}\right)^{2}}{W S^{Q}\left(C-C^{P}\right) S^{Q} W^{\prime}}
$$

This approach is useful for weighting different assets in our portfolio as seen in Table 2, which helps us to maximize the returns and minimize the risk on our investment portfolio. As an empirical demonstration, we use the correlation matrix obtained from NSM stock returns on the various assets considered in the NSM from 2009 to 2013 for some selected assets. The assets are 7UP, ABC Transport, Access Bank, AgLevent, AIICO Insurance, Air service, Ashaka Cement, Julius Berger, Cadbury Nigeria Plc, CAP, CCNN, Cileasing, Conoil, Contisure, Cornerstone, Costain Construction, Courtvile, Custodian, Cutix Cables and Dangote Cement. We compute the realistic empirical correlation matrix for some assets already considered in the RMT as shown below.

\section{Empirical Result and Data Analysis}

\section{Eigenvalue analysis}

We took a sample study of eighty-two $(N=82)$ stocks from the Nigerian stock exchange totalling $L=1019$ daily closing prices and that of the Johannesburg stock exchange, JSE we had a sample study of thirty-five $(N=35)$ stocks with a total of $L^{\prime}=1148$. For NSM, as shown in Figure 2, the theoretical eigenvalue bounds are respectively $\lambda_{-}=0.51$ and $\lambda_{+}=1.65$ with $Q=\frac{L}{N}=12.41$. Furthermore, the market value shows that the largest eigenvalue $\lambda_{1}=4.87$ is approximately three times larger than the predicted RMT of value (1.64).

Figure 3 presents the distributions of eigenvectors for the various eigenvalues in the empirical correlation matrix. The panel labelled U82 represents an eigenvector component for a deviating eigenvalue in the theoretical region, whereas the other 4 are the eigenvector components of the eigenvalue within the regions predicted from the random matrix theory. 


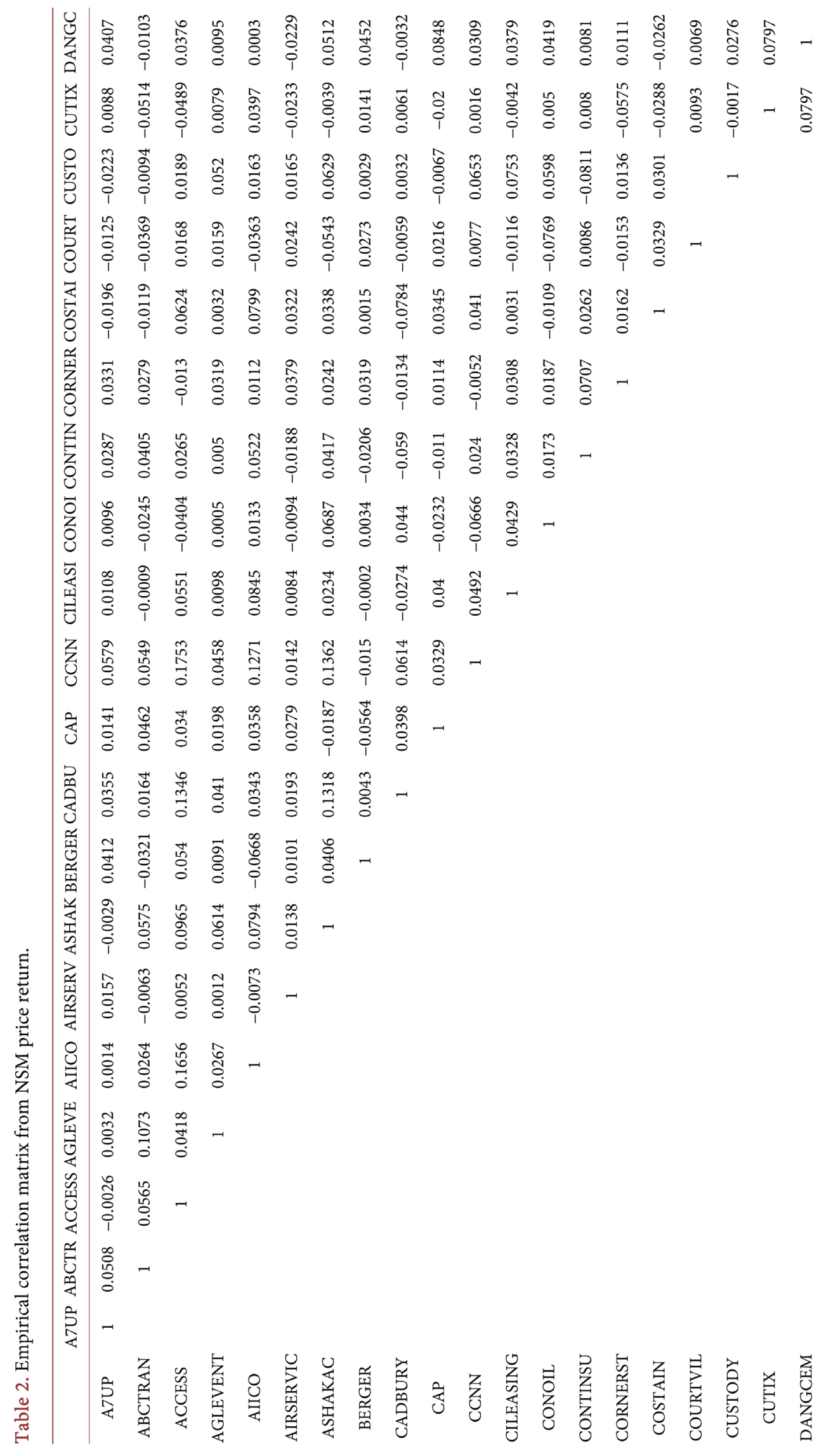



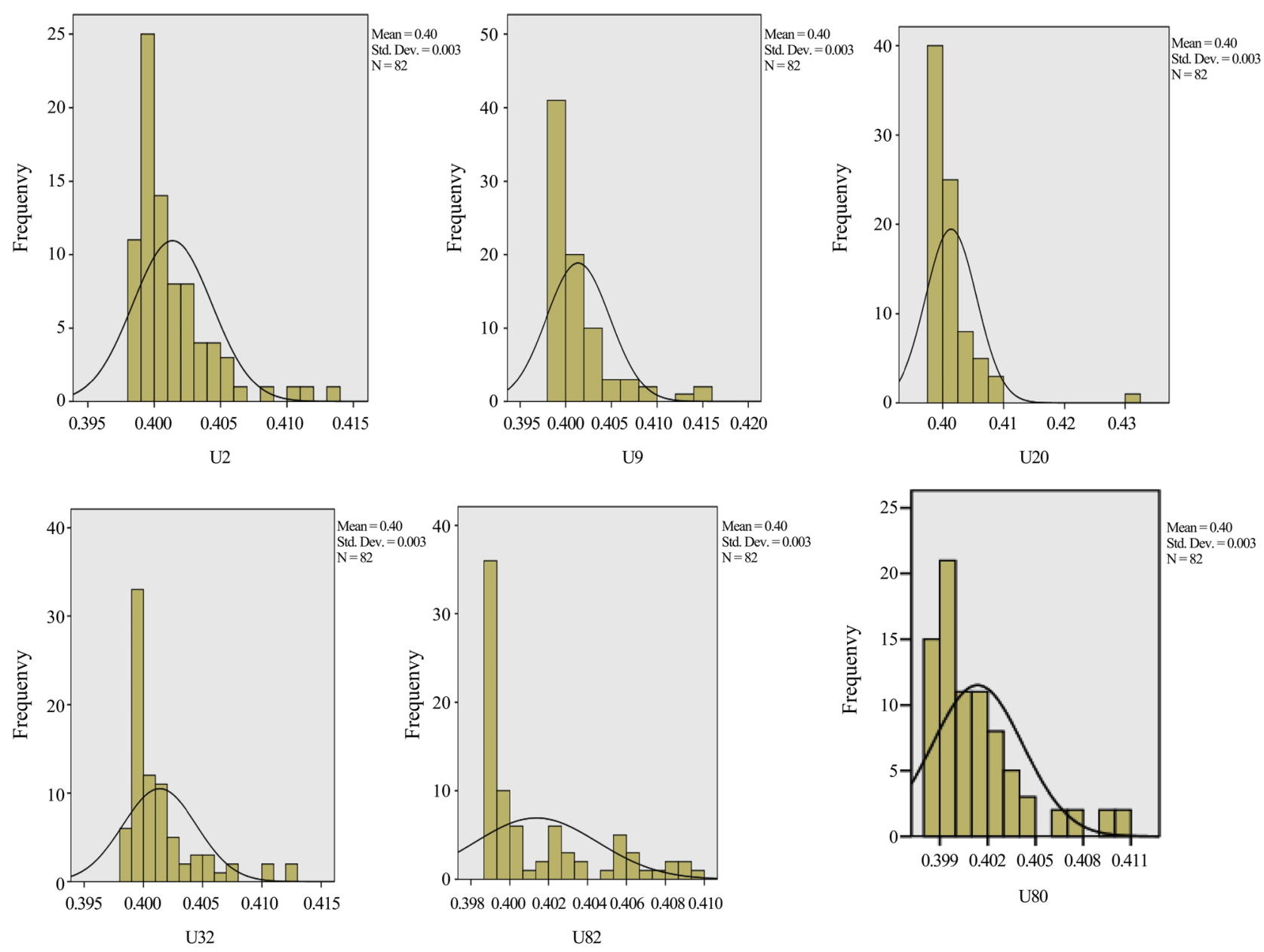

Figure 3. Distribution of eigenvector components of stocks in NSM.

The inverse participation ratio (IPR) depicted in Figure 4 is the multiplicative inverse of the number of eigenvector components that contribute significantly to the eigenmode, [50]. For the largest deviating eigenvalue from the RMT bounds, almost all the stocks contribute to the corresponding eigenvector, thereby justifying treating this eigenvector as the market factor. The eigenvector corresponding to other deviating eigenvalues show that their corresponding stocks contribute slightly to the overall market features in the NSM. The average IPR value is around 3/82 for NSM larger than would be expected $1 / N=0.01$ for NSM, if all components contributed to each eigenvector, [49] [65]. The remaining eigenvectors appear to be random with some deviations from the predicted value of $3 / N=0.04$ possibly because of the existence of fat tails and high kurtosis of the return distributions. The latter are aspects of stylized facts of asset returns in the NSM which describe related market dynamics and therefore underpin SSMCD research and applications ([3], [6] and [7]).

\section{Realistic Implied Correlation Matrix Computations:}

Suppose we had the following weights and implied volatility (computed from option prices) for the under listed assets drawn from the NSM. 


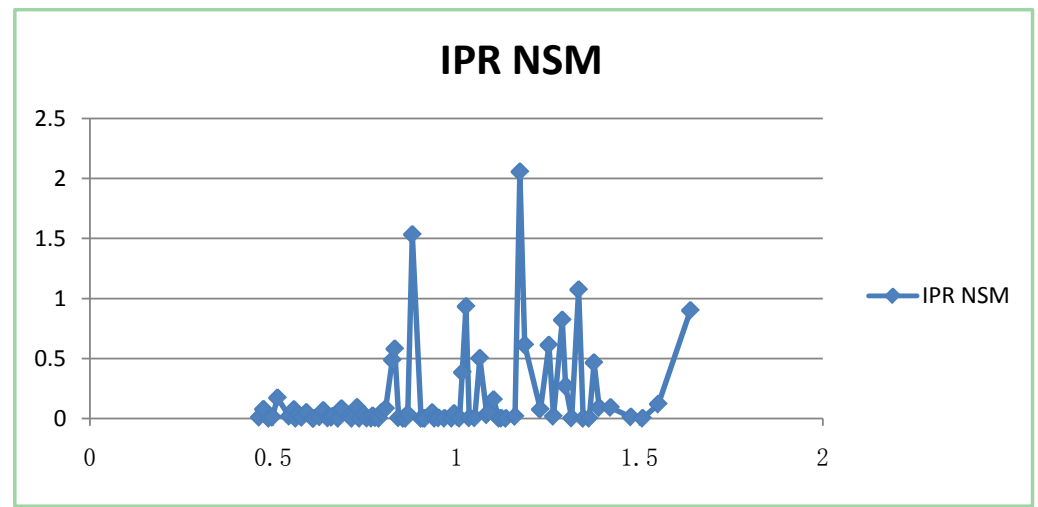

Figure 4. Inverse participation ratio and their ranks for NSM.

The hypothetical or assumed weights and Implied volatilities are represented as weight

$$
\begin{aligned}
W= & {[0.05,0.08,0.01,0.04,0.03,0.06,0.01,0.03,0.05,0.07,0.02,} \\
& 0.04,0.02,0.07,0.09,0.04,0.02,0.07,0.12,0.08]
\end{aligned}
$$

And their corresponding implied volatility represented by

$$
\begin{aligned}
S^{Q}= & {[0.36,0.26,0.30,0.10,0.15,0.20,0.25,0.40,0.19,0.24,0.38,} \\
& 0.27,0.10,0.22,0.21,0.40,0.28,0.30,0.16,0.29]^{\prime}
\end{aligned}
$$

Thus, from the asset return from NSM the empirical correlation matrix $C^{P}$ in Table 2, the eigenvalues of the matrix $C^{P}$ are

$$
\begin{aligned}
& {[0.71,0.79,0.81,0.82,0.83,0.86,0.89,0.92,0.95,0.95,} \\
& 0.98,0.99,1.06,1.094,1.11,1.12,1.15,1.16,1.121,1.60]^{\prime}
\end{aligned}
$$

In the implied volatility analysis, the entries of the vector $Q^{S}$ are used in the diagonal matrix form in Table 3.

Thus, the minimum eigenvalue of $C^{P}=0.71$ which shows that $C^{P}$ is a valid correlation matrix. Therefore, to estimate the realistic implied correlation matrix $C^{Q}$ from the assumed implied volatility for the given portfolio consisting of twenty assets, assume that the implied volatility of the portfolio $\sigma_{\text {port }}^{Q}=0.05$. From the previously assumed hypothetical weights, the weights of the respective assets are

$$
\begin{gathered}
W=[0.05,0.08,0.01,0.04,0.03,0.06,0.01,0.03,0.05,0.07,0.02, \\
0.04,0.02,0.07,0.09,0.04,0.02,0.07,0.12,0.08]^{\prime}
\end{gathered}
$$

and their corresponding implied volatilities represented by the above-specified vector of implied volatilities, $Q^{S}$.

We now use Equation (19) and the respective values of $W, S^{Q}, C^{P}$, to calculate $\sigma_{\text {port }}^{P}$.

$$
\sigma_{\text {port }}^{P}=S Q R T\left(W * S^{Q} * C^{P} * S^{Q} * W^{\prime}\right)=0.0361
$$

Since $0.05>0.0361 \rightarrow \sigma_{\text {port }}^{Q}>\sigma_{\text {port }}^{P}$, we replace $C$ in Equation (24) by an equivalent $20 \times 20$ identity equicorrelation matrix to obtain the value of $w$. 


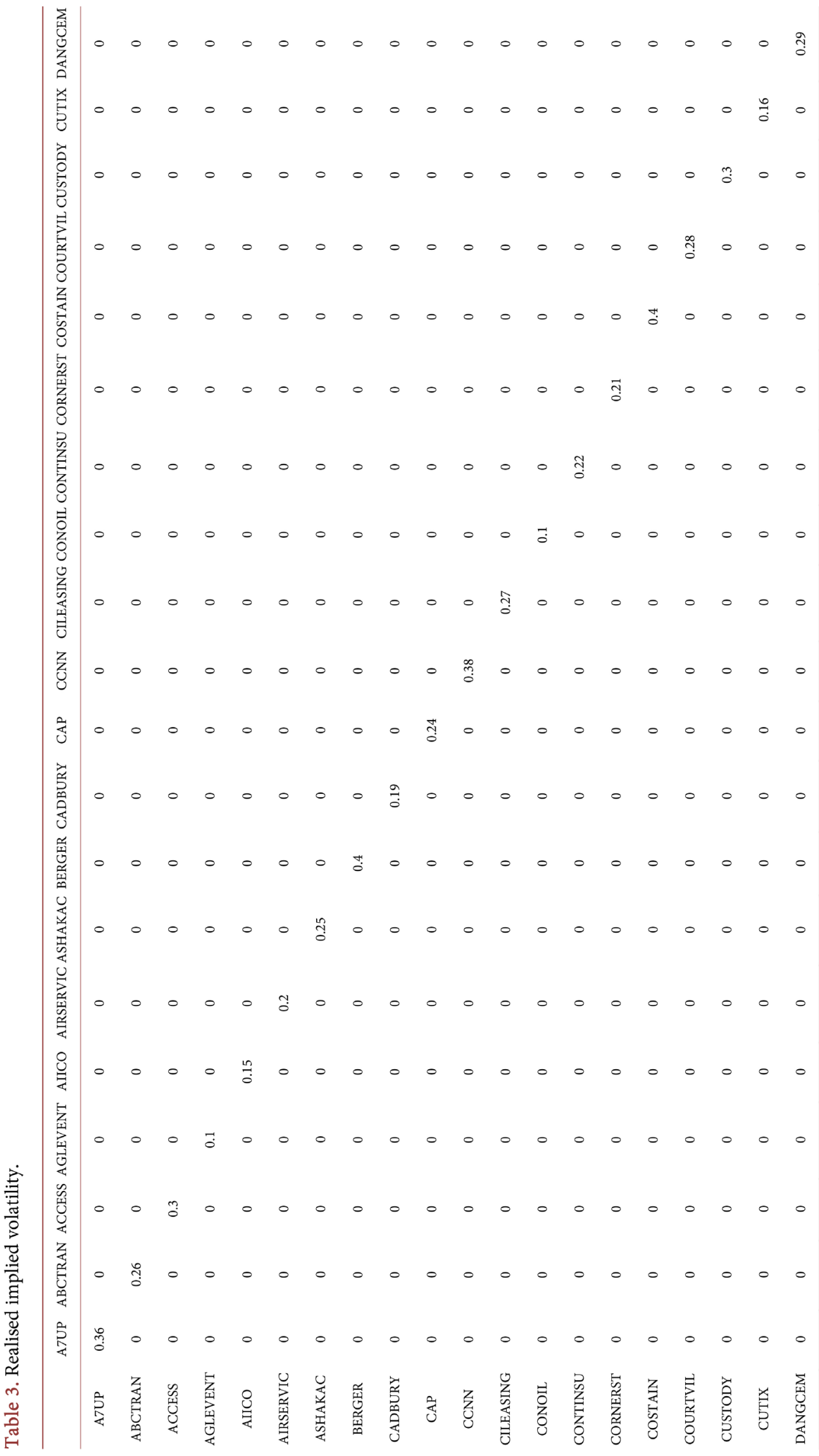




$$
\begin{gathered}
w=\frac{\left(\sigma_{\text {port }}^{Q}\right)^{2}-\left(\sigma_{\text {port }}^{P}\right)^{2}}{W * S^{Q} *\left(I_{20 \times 20}-C^{P}\right) * S^{Q} * W^{\prime}}=\frac{0.0016-0.0013}{W * S^{Q} *\left(I_{20 \times 20}-C^{P}\right) * S^{Q} * W^{\prime}} \\
=\frac{0.0003}{-6.5737 e-04}=\frac{0.0003}{-6.5737 e-04}
\end{gathered}
$$

Therefore, $C^{Q}=C^{P} *\left(I_{20 \times 20}-C^{P}\right)$. The eigenvalues of

$$
\begin{aligned}
C^{Q}= & {[0.57,0.69,0.72,0.74,0.76,0.80,0.84,0.89,0.93,0.93,0.96} \\
& 0.98,1.09,1.14,1.16,1.18,1.22,1.23,1.30,1.98]^{\prime}
\end{aligned}
$$

from which we obtain the minimum eigenvalue to be 0.57 showing that $C^{Q}$ is also positive semi-definite. We now verify our solution from Equation (18) to compute the variance of portfolio using the obtained realistic implied correlation matrix $C^{Q}$ obtained above:

$$
\sigma_{\text {port }}^{P}=S Q R T\left(W * S^{Q} * C^{Q} * S^{Q} * W^{\prime}\right)=0.04 \text { as required. }
$$

The above analyses have provided the necessary data for a hypothetical analysis of implied correlation in the NSM, carried out in this research using the concept of RMT. As noted above, the Marcenko-Pastur eigenvalue distribution predicted that the theoretical eigenvalues should be in the range of 0.52 and 1.65 for NSM. It was observed that 6 out of 82 stocks considered have corresponding eigenvalues outside this theoretical bound of eigenvalues, therefore, $89 \%$ of the information from the return distributions is purely random. Hence, only $11 \%$ of the stocks generate non-random information in the NSM for the study period.

The correlation matrices used in the RMT analyses contain some relevant information for options pricing and hedging [56]. The realistic implied correlation matrix $C^{Q}$ has positive coefficients meaning that the respective stocks move in the same direction hence the diversification method in the portfolio is not an optimal portfolio strategy. It is, therefore, important to invest in some derivative products like call and or put options to hedge against portfolio risks. Further work needs to be done in using a basket of options, equity, commodities, and real estate assets to hedge against exchange rate risks, especially in emerging markets like Nigeria and South Africa. As Nigeria has started trading on foreign exchange futures, the emerging market data will be available for empirical application of implied correlation matrix in hedging exchange risk in Nigeria. That said, to initiate the derivative pricing in the NSM requires the use of RMT and heuristic analysis of NSM and JSE stylised facts to determine plausible derivative prices that will fit the observed stylised facts in the NSM [7].

\section{Links among RMT Results, Macroeconomics and SSMCD}

As noted in [20], the implied correlation matrix is useful for hedging foreign exchange risks. Large corporations typically do this by using a basket of options instead of separate put options for the different countries they invest in [32]. This mitigates against unnecessary exchange rate losses they might incur in the event of rising values of domestic currencies associated with their investments 
[57]. For example, a manufacturing firm in the United States that sources its raw materials in Nigeria, Ghana, and South Africa and pays for its operations in those countries in local currencies, will be exposed to exchange rate risk. To hedge against the risk of falling United States dollars against Naira, Cedi, and Rand, the manufacturing firm uses a basket of options in its risk management strategy. The company could therefore directly buy an option on a basket of currencies at a lower price than it can purchase through separate options on the individual currencies. This is possible with historical return time series correlation discussed in this paper. The major concern will then be the weights to be assigned to individual stocks (or currencies). For optimal investment portfolio, we need to predict correctly the future correlations of respective option values by observing the correlations throughout the life span of the option.

Authors [19] present a detailed analysis of the cross-correlations of traded assets in the NSM using Random Matrix Theory (RMT). This exploits the eigenstructure of the correlation matrices to determine the relative noisiness or informativeness of the correlations. The heuristic modelling of JSE-NSM asset and derivative price dynamics is described in [7]. The heuristics aims to combine JSE derivatives data with broader NSM stylized facts and characterisations, especially based on Random Matrix Theory (RMT), to simulate plausible derivative models and prices that will fit the Nigerian stylized facts and RMT results better. We note here that such characterisations constitute the derivative pricing facet of SSMCD work, in so far as derivative products are essential tools in investing. These products include currency options, cross-currency swaps, deliverable and non-deliverable forwards. Also, important market sectors in these considerations are banking and financial services, telecommunications, energy and (agricultural) commodity derivatives such as futures, because of the strategic relevance of energy and agriculture sectors in the Nigerian economy. Also, banking and financial services are fundamental sources of development finance for investors (households, firms and government). Oil and gas provide the energy inputs into manufacturing and production of goods and services and revenues for Nigeria, and agricultural products support other industries.

The SSMCD connections with these ideas consist in analysing share prices and returns data from different sectors of the NSM such as mentioned above, in light of stylised facts of the market, the six market issues where appropriate (efficiency, bubbles, anomalies, volatility, valuation, and predictability) and RMT correlation diagnostics within the sectors, across the sectors, and, for derivative pricing, implementing the heuristics benchmarked on the JSE. Research pioneered in the Statistics, Information Modelling and Financial Mathematics (SIMFIM) research group, Sheffield Hallam University, UK, and intensified in the Schools of Statistics and Information Modelling and Global Economics at the International Centre for Research and Enterprise Development (ICRED), www.oseluxworldhero3e.com, has characterised the banking sector of the NSM involving twenty-five major banks, [58]) and [6]. The market features examined include stylised facts [6], market efficiency, bubbles, anomalies and volatility 
[59]. Also, SSMCD work was initiated in a related and currently on-going PhD research on "Macroeconomic Modelling of Oil Prices and Financial Variables Libya and Nigeria". The perspectives covered include stylised facts, the four market features explored in [58] and additional work on macroeconomic modelling of selected stock market and economic indicators from the two economies, namely interest rates, consumer price index, inflation rate, exchanged rate, stock market capitalisation and returns. The macroeconomic modelling uses vector autoregression (VAR) and vector error correction (VEC) models to explore the comparative multivariate co-movements of these variables, impulse response functions (IRFs) and persistence modelling of how observed effects vary and persist over time.

The portfolio theory and management aspects of SSMCD are embodied in a recently submitted $\mathrm{PhD}$ thesis also supervised by the first author and entitled "Mathematical Analysis in Investment Theory: Applications to the Nigerian Stock Markets [60]. The key objectives include: 1) to review the mathematical foundations of portfolio theory and optimisation based on the Markowitz model [47] [61], in order to determine the strengths and weaknesses of the model; 2) to examine the mathematical properties of different risk measures which underpin investment and portfolio theory, and extend the Markowitz model to accommodate such risk measures; 3) to more generally explore the mathematical analysis of investment systems in order to determine the interactions among securities in investment portfolios and how to better optimise the portfolios (this is where RMT plays a role); and 4) to apply the results to investment portfolios and schemes in the NSM.

It is noted in [3] that these studies are literally "the end of the beginning", since to characterise different sectors of the NSM will require a swarm of PhD students and at least two supervisors each, say, for 100 students and 200 supervisors. To do this across key African markets, for example the SANE countries (South Africa, Algeria, Nigeria, and Egypt), will require even more researchers. This effort necessitates a coalition of Nigerian, African and international academics and professionals in mathematics, finance, statistics and economics. For this purpose, we have convened a Nigerian Mathematics, Finance, Statistics and Economics Research Consortium (NIMFSERC) using seed grant from the British Council. This consortium co-led the $20151^{\text {st }}$ International Symposium on Mathematical and Statistical Finance with Emphasis on Bank Financial Management and Economic Development, held at the University of Ibadan, Oyo State, Nigeria [12]. Paper [3] derives from a remark in the symposium proceedings calling for a masterclass in stochastic modelling and SSMCD of a typical stock market like the NSM. The spectrum of SSMCD research articulated in that paper and the current paper requires an ambient pool of research on global economics, for which reason we instituted the School of Global Economics in the ICRED to champion not only NSM works of this ilk, but also SSMCD research across Africa, for example. [3] highlights related SSMCD ideas in [8], [9] and [4] as follows.

[8] is a magisterial post-2007 financial crisis autopsy of what went wrong in banking, finance and macroeconomic modelling, aptly titled "The End of Alc- 
hemy. Money, Banking and the Future of the Global Economy". For want of space, we simply note that, written by a former Governor of the Bank of England, the text strongly underpins future work in SSMCD, linked to macroeconomics. It posits answers to a range of poignant questions and issues which will help investors and policy makers to extract cogent lessons from the financial crisis and responses to its consequences by the global financial system. These questions and issues include: 1) the need to more carefully explore the role of money and banking in enhancing competitiveness in a market economy, national industrialisation, and higher living standards; 2) poor understanding of how the world economy works which provokes a need for streetwise economics and improved short- to medium-term predictions of financial market trends [4];3) avoiding the pitfalls of the "monetary elixir" engendered by the creation of paper money, for example hyperinflation, stagflation, sluggish economic growth, rising unemployment, and financial crises; 4) importance, therefore, of policies by central banks and governments to stabilise financial systems and balance national budgets; 5) the key question: "Why have money and banking, the alchemists of a market economy, turned into its Achilles heel" and how do we save the global economy from these malaises ([8], p. 5)?; 6) why do macroeconomic models fail, especially models which explore "swings in total spending and production" without adequate consideration of the importance of money and banks? 7) is there a fundamental weakness in the intellectual economic framework underpinning contemporary economic management? 8) the need to master the four key concepts that explain macroeconomics-disequilibrium, radical uncertainty, the prisoner's dilemma, and trust' ([8], p. 8), for example radical uncertainty "refers to uncertainty so profound that it is impossible to represent the future in terms of a knowable and exhaustive list of outcomes to which we can attach probabilities" (an uncertainty that sometimes engenders large disequilibrium), and the prisoner's dilemma is the difficulty of achieving the best outcome when there are obstacles to cooperation (ibid, p. 9); 9) how do we improve our understanding of disequilibrium in economies and better deal with the prisoner's dilemma in economic management, by building models that do not fundamentally assume that rational market participants will lead economies to efficient equilibrium (which connotes inefficient markets)? 10) the need to reduce the cost of lost output (productivity) and employment arising from improper management of money, banking and financial crisis; 11) the imperative to critically analyse the lived histories of economic experiments right from the first world war, related to money management, exchange rates, structure of the banking system and financial regulation architecture, inflation targeting, financial stability, hence monetary and fiscal policy, and creation of governing rules that inform better investment and policy making results by households, firms and governments (see also Figure 1, [3] [9] [10]); 12) how do we build predictively useful early-warning and antifragile financial systems which mitigate the incidence of unsustainable stabilities and imbalances in the global financial system? 13) why, following the biggest monetary stimulus in response to the 2007 global financial 
crisis is the world recovery so slow after 11 years till $2018 ?$

The above questions and issues are just a few of so many posed in [8]. They show clearly that there are several fallacies in economic management and investing which arise because there is insufficient characterisation of stock markets and financial systems under different conditions of uncertainty, financial reforms, crisis, financial stability versus instability, all complicated by occasional tendencies to deglobalize such systems. This reinforces the need for continuing SSMCD work that takes these questions and issues into consideration and deploys different models, interpretations and experimental investigations in resolving them. The notes also show the set of variables that should be explored in doing so, in addition to stylised facts of asset prices and the six market issues. Figure 1 also captures so many of these variables whilst Table 1 shows the different areas of financial mathematics where specific SSMCD applications will be implemented. See also the scope of global economics research that ties up these facets in the ICRED School of Global Economics (www.oseluxworldhero3e.com). We will have more to say in these regards in future articles on SSMCD.

[9] augments the above notes with a rules-based system for making sense of the rise and fall of nations, based on similar thinking about the workings of financial markets and related economic management. Again, for economy of space, we simply indicate some of the rules, and argue that they enlarge our empirical finance and economics toolkits for implementing the nature of SSMCD work envisaged in this paper. These rules include: 1) the fact that economic realities are impermanent (radically uncertain); 2) hence, the need to model and forecast economic trends regarding GDP growth, income growth, consumption, job losses, inequality, wages and working conditions, (commodity) exports, oil prices, inflation, exchange rates, foreign debts, investment sentiments, capital inflows and outflows, business cycles, and other macroeconomic variables on a short- and medium-term basis of 5 - 10 years; 3 ) the need to avoid "anchoring bias" in the analyses, which is a predisposition to believe that good times will last forever; 4) also the need to avoid "confirmation bias" in economic analyses which is a "tendency to collect only the data that confirm one's existing beliefs"; $5)$ the empirical reality that economic growth typically implies economic development so that an overemphasis on health, education and other measures of human development in modelling is a "false choice" of variables in macroeconomic modelling; 6) the irrelevance of simple straight-line forecasting based on one dominant variable versus inclusion of relevant numerical (credit, prices, money flows, interests rates, for example) and qualitative factors like shifts in politics, policy and sentiments; 7) a requirement to watch for balanced growth and focus attention on a "manageable set of dynamic indicators that make it possible to anticipate turns in the [economic] cycle"; 8) the need to focus on investments more than on consumption, because it primarily drives job creation, innovation and increases in productivity; 9) the importance of using easy-tomeasure productivity factors like population forecasts which depend on few factors like fertility and longevity and are more accurate than other measures of 
productivity; 10) using labour force growth and real skills as opposed to mere certification; and 11) the need to "capture all the delicate balances of debt, investment, and other key factors required to keep an economy humming".

The above notes define the practical art of global economic analyses for which the essential question should not be, in [9]'s words: "What will the world look like if current trends hold?" but "What will happen if the normal pattern holds and cycles continue to turn every five years or so?". [4] and [10] epitomise similar rules in their principles for life, work and investments. The texts explain how a keen eye for what really works helps the investment firm Bridgewater Associates to collate detailed insights on the driving forces of change in the global economy, develop rules that enable the company to "embrace reality and deal with it", and importantly convert the rules to automated investment algorithms, thereby achieving better awareness of economic trends and impressive year-on-year profits. For example, the system enabled Ray Dalio, Chairman of Bridgewater, to correctly call the global financial crisis when conventional economists and central bank policy makers could not do so, due to anchoring bias on the continuity of the Great Stability that prevailed about a decade before the crisis.

What the SSMCD adds to the above knowledge is the use of DNA-style systematic characterisations of financial market trends and features to deepen our understanding of economic realities facing a country. This enhances the predictive power of investment and economic models used to make practical sense of often complex economic realities, within short enough periods that are not longer than typical span of business, technology, and political cycles, about 5 years, but with proactive management of investment funds year to year.

\section{The Nexus among SSMCD, Global Economic Trends and Genome-Informed Econome}

[62] notes that the UK economy "will go into meltdown with a collapse in house values, a slide in the strength of the pound, surging inflation and soaring interest rates if Britain leaves the EU without a Brexit deal", as predicted by the Bank of England. Indexed to a base level of GDP in Q2 2016, the Bank of England modelled a set of scenarios using different assumptions about Brexit, namely: No deal and no transition; Disruptive transition; Disorderly transition, informed by how close the Economic partnership between UK and European Union is (Less close to Close). The analyses also considered Unemployment and Inflation Brexit Scenarios. The results demonstrate that in all scenarios the No deal scenario came out far worse than the other scenarios. The GDP could fall by $8 \%$ in 2019 , with a "near doubling in unemployment to 7.5\%", "a leap in inflation to 6.5\%". An increase in Bank of England base interest rate to 5.5\% could slump house prices by a third and the pound could slide in value by $25 \%$ against the US dollar and euro. These facts exemplify the kind of economic analyse and management decisions carried out by central banks and related policy think tanks, and the 
focus on the key variables hinted in the foregoing notes. We reiterate the fact that over a longer horizon such analyses would require a fuller SSMCD-like modelling using a spectrum of variables in Figure 1 and indicated by the questions, issues, and rules explored in [8] and [9], for example. These analyses will be informed by macroeconomic theories and the empirical finance realities discussed above and in [1].

In a recent text [10], Ray Dalio presents economic principles for navigating big debt crisis. The text complements [4]) in exploring cause-effect relationships among key financial markets and macroeconomic policy variables related to different financial crises. Using detailed analysis of economic history to understand the economic mechanisms that drive huge credit cycles, Dalio notes that the "downside risks of having a significant amount of debt depends a lot on the willingness and the ability of policymakers to spread out the losses". We argue that these points reinforce the need for SSMCD research which connects financial markets and macroeconomic management research as explored in this paper.

We now summarise the analogies that relate SSMCD research to the genome and culminate in what, for the first time in empirical finance literature, we term the econome. Authors [63] talk about the following constructs in molecular biology. First is genetic engineering which alters (edits, cuts, repairs, transfers) genes within and between biological entities. In SSMCD terms, we think of the manipulation of SSMCD knowledge and informatics for effective investing, economic management, and policy decisions. Second is the use of a pioneering technique such as Crisp/Cas9 to alter the genetic material of an animal or human. This requires understanding of the structure of a cell (cell, nucleus, chromosome and DNA within the nucleus) and three key steps: 1) synthetic guide molecule locates target strand of DNA; 2) Crisp/Cas9 cuts both strands of the double-helix DNA; and 3) repair enzymes are used to close the resulting gap, thereby changing the genetic code.

In SSMCD terms, the cell structure is roughly analogous to the market microstructure at overall level of the market. For market subsectors, it is equivalent to pooled market understanding of the stylised facts of asset prices within the sectors and across different asset classes (equities, bonds, commodities, derivatives, real estate, for example). The nucleus and DNA of the (sub)market constitute the combination of stylised facts, market issues, macroeconomic impacts, policy and regulatory regimes which summarise the current state of knowledge regarding the underpinning market dynamics. Synthetic guide molecule is roughly analogous to a combination of systematic rules and algorithms which explain and forecast the dynamics, for example the data-driven rules explored in [4] and [10]). Crisp/Case9 technique is itself akin to the SSMCD systematics. Repairing enzymes refer to suites of investment and firm management strategies informed by the SSMCD econome.

The object in genetic engineering concerned with identifying specific genes affecting different disease conditions (cancer tumours, HIV, sickle cell, say) is akin to using the SSMCD system to identify investing, economic management, 
market development and policy-making gaps in a market. Tweaking a gene to possibly cure a disease is analogous in SSMCD terms to smart decision making along these lines, same as Bridgewater makes, to correctly call and excel better than competing firms during the 2007-2009 global financial crisis.

For a picture of how SSMCD systemics should support smart decisions in financial markets on the part of investing firms say, we explore further analogies which flow from the June $11^{\text {th }} 2016$ Technology Quarterly newsletter in The Economist, pp. 3-12, 77-78. Technology-led agriculture operates like a manufacturing operation. SSMCD systemics also envisages to automate financial market analytics and decision making, as in [4] [10], but reinforced by additional perspectives explored in this paper. Wiring up farms like lab rats connotes the development of SSMCD decision making sensors which indicate, measure and forecast changing market dynamics, as do sensors for soil moisture and fertiliser doses, for different types of crops. The idea that farms "are becoming like factories: tightly-controlled operations for turning out reliable products, immune as far as possible from the vagaries of nature", due to better understanding of DNA, reminds us of the use of SSMCD systemics to automate trading in different asset classes, by monitoring relevant behaviours of the investment variables discussed in this paper-those evident in Figure 1 and those suggested in the key references mentioned above.

At macroeconomic and economic management levels, the ten rules in [8] and [10] apply. Creating new financial products in the NSM through comparative NSM-JSE RMT analyses and derivatives pricing as foreshadowed in this paper illustrates the idea of turning out reliable products. Immunity from vagaries of nature is akin to portfolio selection and management, to reduce risks and maximise returns. Shifting whole genes between species in early genetic engineering, as opposed to detailed within-species gene editing "down to a single genetic letter", is analogous to cross-sector portfolio construction in investing. Hence, understanding a crop's DNA sequence tantamounts in SSMCD terms to having the SSMCD econome of a firm or a market sector,-that is, its economic DNA. This means that investing decisions can be smarter and more precise.

The upshot of these SSMCD innovations is that investment business models, capital management and global economic management systems will be transformed into "matrix-crunching software platforms" which mimic integrated farm management platforms. We are aware that such systems are currently used in algorithmic trading by investment banks and hedge fund managers like Goldman Sachs and Bridgewater Associates. Hence, we will explore what additional insights flow from SSMCD research for improving such platforms, and the nature of cloud and parallel computing systems including data science, big data analytics, and artificial intelligence frameworks that support effective decision making using the research results.

Interestingly these analogies inform the nature of experimental economics that can create catalogues of economic and investment analyses, and policy making scenarios that will help investors, firms, governments, and policy makers to 
make smarter decisions. In an article by Harper [64] embedded in The Economist's Technology Quarterly report on the Future of Agriculture, it is noted that what is more exciting about manipulating botanical genomics, for example, is the "physical instantiation" (phenotypes) of the products which feed the world, and that this is a product of "both genes and environment". Just as Harper optimises phenotypes by manipulating the environment under the auspices of the Open Agriculture Initiative (OAI) at the MIT Media Lab, we work to create and optimise investment and economic decision modelling in the School of Global Economics and Capital Management at the International Centre for Research and Enterprise Development (ICRED), www.oseluxworldhero3e.com.

The concept of "environment" here is related to the need to run experimental economics and finance laboratories within country-, sector-, and firm-specific investment and macroeconomic management contexts. This is because, as shown in Figure 1, there are different forms of capitalist market structures within which different countries and their trading firms operate. For example, the contexts surrounding the NSM and JSE are different, same with the different firms and sectors within them. SSMCD-related "environmental information" occur at different levels of granularity, for example within firms, sectors, across sectors, at overall market levels, for different asset classes, continentally for African markets say, and globally. Hence, SSMCD work contextualises market know-how to financial products that succeed in these different environments. This means that systems of research collaborations and structures are required to finesse the results accordingly, and subject emerging products and services to continual experimental modelling, testing, and release into the appropriate markets.

In the ICRED, we synergise the requisite analytics using collaborative research in such contributing schools as Statistics and Information Modelling, Advanced Multidisciplinary Studies, Integrated Business Analytics and Development, Computing and Information Technologies, Global Economics, and Global Business. There are in these schools related spin-offs from the research results and importantly specialist institutes and constellations of research groups and enterprise development work involved. The following vignette captures the spirit of these structures for the School of Global Economics, whilst the details for other schools are available at www.oseluxworldhero3e.com.

A vignette of SSMCD-related research and enterprise development in the ICRED Oselux School of Global Economics and Capital Management

In the Oselux Global Economics and Capital Management, simply referred to as the School of Global Economics, we conduct deep BSc-, MSc- and PhD-level theoretical and applied economics research, to provide the most robust evidence base for effective decision making under conditions of uncertainty and complexity.

\section{The SSMCD remit}

This is hinged on broad and deep characterisations of key sectors of an economy to elicit fundamental and contingent predictors of value in the sectors, 
and for the wider economy. An example is Systematic Stock Market Characterisation and Development (SSMCD), which links key empirical market features (efficiency, anomalies, bubbles, volatilities, predictability and valuations) to macroeconomic factors like interest rates, inflation, consumption, investments, growth, and unemployment.

Mapping the DNA of overall financial markets and key sectors this way (energy, banking and finance, health, telecommunications, retail, and industrials, for example), combines with related applied statistics, financial mathematics, investing, applied economics, computational modelling, and business analytics knowledge, to produce a multiple-lensed view of economic and investing phenomena.

\section{Key perspectives of work in the School are:}

- Innovating leading university curricula in Economics, for instance Nottingham, Oxbridge, Warwick, Harvard, Princeton, MIT, and LSE;

- BSc, MSc and PhD training in Financial Mathematics, including derivatives research, portfolio theory, and investment applications in global financial markets;

- BS, MSc and PhD training in Applied Statistics, Actuarial Science, and Global Economics courses;

- Researching and investing in different asset classes-equities, bonds, currencies, commodities, real estate, and derivatives;

- Implementing paper trading experiments in portfolio construction and management; see Timothy Ferriss (2011)'s The 4-Hour Week, p. 190);

- Special programmes for Cryptocurrencies (Bitcoin and the ilk) investment research, market characterisation, and investing strategies;

- Links with business and finance;

- Advanced time series and econometric analyses;

- Bank financial management (retail banking, investment and wealth management, for example);

- Applied economics, including economics of strategy, financial economics, monetary policy;

- Experimental and behavioural economics linked to the social-psychology of investments;

- International private equity and valuations;

- Entrepreneurial finance;

- Understanding and doing business with global central banking e.g. US Federal Reserve, UK Bank of England, Central Bank of Nigeria;

- Street-Wise Economics: Case Studies built from emerging and typically multidisciplinary hot topics;

- Other emerging perspectives from daily general cultural literacy work in Worldhero $3 \mathrm{E}$, which generate valuable wisdom of the crowds, surveys of experts, and financial journalism;

- Applied Economics Newsletter, practical financial journalism which digests and creatively extends critical reads, blogs and informed conceptual articles 
from journals and financial broadsheets such as The Times, The Economist, using Worldhero 3E research and businesses as case illustrations;

- Regular international symposia, schools and workshops in global economics, mathematical and statistical finance, in collaboration with experts from academia, industry and government, linked to national socio-economic development goals and challenges;

- Finance, Economics and Society: Knowledge, People, Methods and Technologies.

\section{Further technical research remits}

[1] Integrated Risk Analysis, Business Intelligence and Communication (IRABIC):

This research strand which will mimic combined perspectives from Putnam's, Gigerenzer's and Kahneman's works at the interface of risk appreciation, heuristics, business intelligence and data mining, psychology of communication, behavioural economics, decision theory, game theory, integrated risk management solutions etc. The strand will also generate text-monographs/journal papers that disseminate research results and associated best practices on IRABIC.

[2] Stochastic Analysis and Mathematical Finance Theory and Applications (SAMFTA):

This strand will explore such topics as: statistics and probability theory; infinite dimensional models; shot-noise effects, incomplete information issues; application of SDEs in Hilbert spaces, including Lévy random fields, to credit risk, CDOs, equity and energy markets; nonlinear filtering theory for pricing corporate securities under noisy asset information; stochastic calculus including stochastic differential equations; stochastic analysis, mathematical analysis, functional analysis, ordinary and partial differential equations; mathematical physics; approximation theory; measure and integration theory; applied mathematics; quantitative finance; stochastic programming \& stochastic optimization models; quantitative risk management; mathematical foundations of investment and risk management, etc. This strand will also generate text-monographs/journal papers that disseminate research results and associated best practices on SAMFTA.

\section{[3] Stochastic Modelling in FIEBB (STOMFIEBB):}

This will implement fundamental and applied research on the interface among: stochastic processes, including applied stochastic modelling in finance, insurance, economics, banking and business (FIEBB); actuarial science; financial economics, including high-frequency finance; corporate finance; financial accounting; business analysis, forecasting; complexity and chaos theory, including fractals; bank financial management; business and marketing, including conjoint analysis, structural equation modelling, customer analytics etc.

[4] Statistical Aspects of Data Mining (STADAM):

This will implement theoretical and applied research in all techniques of data mining e.g. neural networks, regression analysis, multivariate analysis, modern time series analysis and forecasting, decision trees, logistic regression, cluster 
analysis, rule associations etc. This strand will also generate text-monographs/ journal papers that disseminate research results and associated best practice on STADAM.

[5] Research directions/workshops in Credit \& Interest Rate Analytics: This will include:

- Design of more sophisticated credit and interest rate products suitable for special client risk management and investment challenges

- Understanding credit derivatives and structured products

- Mathematical models and case studies for/of pricing financial derivatives

- Strong real-life exemplification of securitization markets, credit instruments, credit default options (CDOs) (including their rationale, origination and structuring), market approaches and models, rating agency approaches.

[6] Research directions/workshops in Extreme Value Theory (EVT) and Copula methods in quantitative finance:

This will include

- Deep understanding of heavy-tailed risks and complex financial interdependencies as rationales for going beyond standard statistical models and simplifying assumptions of normality, in order to develop more sophisticated methodologies

- Overview of the role of EVT in modelling and measuring extreme risks

- Overview of the role of Copula functions in modelling co-movements between markets, risk factors and other variables studied in finance

- Detailed look at core topics in this body of techniques: theory of maxima; Fisher-Tippett Theorem; Maximum Domains of Attraction; Block Maxima Method for EVT; and Coping with Copulas; Types of Copulas; Fitting Copulas to Data; Application to Credit Risk (for Copula methods).

Related research and enterprise development perspectives:

- Oselux Financial Education: including Oselux MMCME Centre, a Centre for Millennials Money and Contemporary Mathematics Education; will teach basic money management to primary and secondary school pupil in Nigeria and Africa, including parents, working with schools; to train more than 1 million primary school students and 1 million secondary school students from the six geopolitical zones in Nigeria; to use am army of Oselux-inspired mathematics, statistics, finance and economics graduates, youth corpers with match-up funding from local, state and federal governments; to develop OseluxFinApp to teach under-18s' about digital money (savings, current accounts, interest rates, investments, compound interests, shares, etc.); to be particularly championed by Oselux Enterprise Bank also in extending the training to SMEs, market women and petty traders, etc.;

- Worldhero 3E Centre for Advanced Research and Enterprise Development (CEfARED), linked to related disciplinary research in mathematics, statistics, computing, information modelling, applied economics, and financial mathematics; 
- Organising national cross-sector multidisciplinary support networks like Nigerian Mathematics, Finance, Economics and Statistics Research Consortium (NIMFSERC);

- Linking these consortia to a global Centre for Mathematical Modelling in Finance, Insurance, Economics, Banking and Business (CEMMFIEBB), which the School of Global Economics coordinates;

- Founding Mathematical Sciences Research Groups (MSRGs) in affiliate universities, to cross-fertilise research in mathematics, statistics, computing, finance, and economics;

- World-leading undergraduate and postgraduate tuition in the contributing subjects;

- PhD Research on the topic: The Pedagogy of Selected Global Economics Disciplines: Entrepreneurship, Enterprise Development, and Employability Perspectives, with specific focus on, say,

- Financial Mathematics, Investing, Fund Management, Econometrics, Applied Economics, Experimental and Behavioural Economics, International Private Equity and Valuations, Bank Financial Management, Wealth Management, Mergers \& Acquisitions, Entrepreneurial Finance, and Financial Journalism.

Related Spin-offs:

- Oselux Capital: Venture capital, international private equity, and investment management-actively implements the research ideas in the School

- Oselux Global Economics Monitor

- 3 E Business Restructuring Group

- SANSED: Society for the Advancement of National Socio-Economic Development, with members trained to peacefully advocate for positive economic change in their countries through

- ESDEMs. Economic and Social Development Movements, for example

- NESDEM: Nigerian Economic and Social Development Movement

Again, as in all ICRED Schools, work in this school produces outstanding corporate academic $\mathrm{PhD}$ theses, MSc dissertations, and advanced project outcomes, which can be spun-off as social enterprises, and for-profit born-global firms that are powered by the Internet.

\section{Conclusions and Hints on Future Work}

In this paper, we explored different pathways for systematic stock market characterisation and development (SSMCD) and the role of Random Matrix Theory (RMT) in SSMCD research, with a focus on the NSM. We noted that RMT maps the correlation structures among the returns of financial assets in a market and provides related analyses using selected NSM stocks. The RMT results shed light on the assets that drive the NSM above the din of market noise. We also used the RMT results to model implied volatility and option prices in the NSM and explained the importance of the results in risk hedging and portfolio management. More importantly, we discussed how the RMT analyses combine with empirical 
finance modelling of stylised facts and key market features of the NSM (efficiency, bubbles, anomalies, volatility, prediction and valuation) to support SSMCD research.

It was noted that SSMCD should be looked at from overall and sectoral levels and we discussed related studies completed in these regards. Further developments in SSMCD were foreshadowed regarding macroeconomic management of an economy linked to stock market analyses. For this, we took a closer look at recent works that suggest ways to mitigate the effects of the global financial crisis [8], [9] and [4] [10]. SSMCD is a form of DNA genomics for financial markets which will inform effective investment decision, national macroeconomic management and policy-making across economic cycles and practically within a 5 10 -year horizon. Table 1 in the paper shows the different flavours of economic analyses involved (asset liability management, alternative investments, behavioural finance, econometrics, high frequency trading, liquidity modelling, risk analysis, time series analyses, and quantitative trading, for example). We explored in some detail genetic engineering analogies which explain the concept of the econome in SSMCD like the genome in molecular biology.

We linked the potential applications of SSMCD thinking to contextualised investment, macroeconomic management, and policy/regulatory decision-making at individual investor-, firm- and government-level modelling environments. The thrust of the applications is to automate the decision-making process in the same way as computer-aided agriculture and manufacturing are enacted. For this, we talked about the role of computational matrix-crunching systems such as cloud computing, data science algorithms, artificial intelligence, and robotics. The idea was to explore additional contributions which SSMCD systemics can make to existing algorithmic trading systems used by investment banks and hedge fund management firms.

We highlighted the requisite constellations of collaborative research structures and efforts required for market-, sector-, national macroeconomic- and continental (African)-level SSMCD research and enterprise development. A vignette on the Oselux School of Global Economics and Capital Management in the International Centre for Research and Enterprise Development, founded by the first author, was presented to exemplify such structures. The vignette shows the centrality of SSMCD research in orchestrating the kind of New Economics envisaged in Figure 1. Combining insights from the variables depicted in Figure 1, the specialist research areas in global economics shown in Table 1 and the above-mentioned vignette, and the additional variables, rules and perspectives captured in the key references used in this paper, paints a mosaic of SSMCD research in mind.

The collation of these insights and their orchestration in improving existing financial instruments, investment services, and macroeconomic management practices, and in creating new ones, is material in SSMCD work so explored. The development facet of SSMCD simply refers to how the findings can be used by the NSM and concerned (African) financial markets to deepen, and to improve the markets and overall national economic performance along the lines sug- 
gested by [8] [9] and [4] [10], for example.

This paper contributes to knowledge in ways portrayed by the following Research Methods Canvas $\odot$ which guides in-depth research in the ICRED as presented in Figure 5 below. The problem studied and why (PS|W) in this paper and related SSMCD work is the need to deepen existing frameworks in mathematical sciences (maths, stats and computing), finance and economics, as relates to investments, macroeconomic management, and policy-making decisions by individual investors, firms and government agencies, within the contexts of a country's financial markets, for example the NSM. The underpinning Domain Knowledge consists of a spectrum of technical areas of research depicted in $\mathrm{Ta}$ ble 1 of this paper, including new perspectives from RMT and SSMCD research, and the pool of modelling variables in Figure 1, all of which are augmented by

The Research Framework: A One-Page Schematic of an entire Research Program

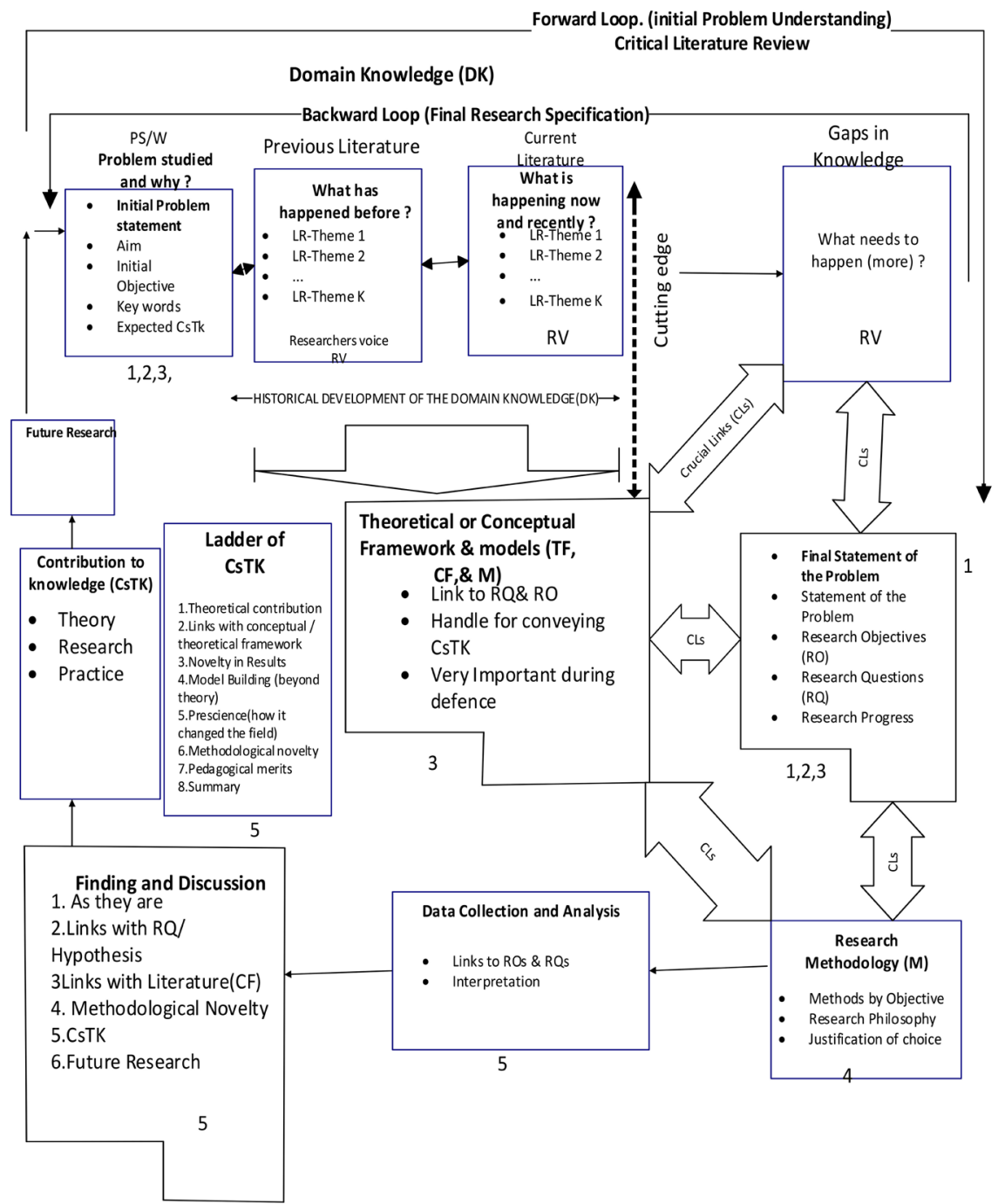

Figure 5. A Research Framework that almost says it all. Source: [66] Grasping the Basics and Stylistics of Effective Literature Reviews and Academic Writing. 
new insights from [8] [9] and [4] [10], for example.

The key gap in knowledge is that whilst SSCMD-like systemics expectedly happen in investment banking and hedge fund management, the character of the models used are shrouded in secrecy, at least to outside researchers and students in universities. It is, therefore, important to explore key SSMCD mechanisms and deliver a spectrum of global economics and capital management training in Nigerian, African, developing countries' and international universities. This training should engage academics, students, and collaborating practitioners in the art-science of model-enhanced, computationally intensive, qualitatively insightful, and radically experimental learning. The structures for this to happen are portrayed in the above vignette on Oselux Global Economics programme. From the authors' knowledge of the economics and finance programmes in $\mathrm{Ni}$ gerian universities, this style of systemic work is not available as individual academics and their graduate students typically work in silos.

To teach finance and economics (indeed any other higher education subject) in line with the canvas, a lecturer should strive to convey a sense of the historical development of the topic through connected literature themes (Themes $1,2, \ldots$ ). For SSMCD-informed pedagogy of global economics, as in this paper, we will explore with the students the meanings and contributions of different facets of ideas explored in the paper to the goals of theoretically sound and practically streetwise economics. The ideas, to reiterate, include market features and stylised facts, investment theories and management practices, macroeconomic underpinnings and predictor variables (monetary policy, fiscal policy, inflation targeting, scenario modelling as in Brexit, for example), emerging questions, issues and rules of play in global economics in light of changes in the global financial architecture necessitated by the 2007-2009 global financial crisis, previous crises, and approaches for optimal management of the effects of such debt-fuelled crises through equitable spread of the losses by central bank policies [10]. The hallmark of the pedagogy is a combination of intensive understanding of the relevant theories and immersive hands-on practices in real and simulated labs.

The elucidation of conceptual frameworks, theories and models which inform the analyses and student projects in this active and reflexive pedagogy is important, but such frameworks should be critically interrogated as to how they support the research objectives (ROs) and questions (RQs). For example, a discussion of Keynesian and post-Keynesian monetary and fiscal policies must reckon with an historical understanding of the mediating contexts of financial crises, and the potential for alternative frameworks to better explain and help to manage the crises [8] [9] [10].

The contributions to knowledge (CsTK) from this paper are now briefly rendered as in Figure 5. Theoretically, it foreshadows the importance of RMT to SSMCD research. The different theories can in future be enhanced by the authors and other researchers within the SSMCD purview. The practice is emphasised to lead to improvements in current approaches to global economics man- 
agement and investing and creation (instantiation) of new financial products and services. The DNA analogies shed more lights on how these practical goals could be realised.

A more ramified look at the ladder of CsTK in Figure 5 suggests the need to: develop the theoretical results significantly along the lines mentioned in the foregoing; explicate alternative conceptual frameworks in so doing, for the different topic areas; ensure sufficient novelty in the results either through relevant extensions of core theories in the contexts of the research (NSM for instance) or creative use of existing results; if possible to achieve prescience in the results which is likely through new insights that SSMCD thinking lends to a topic; similarly to achieve methodological novelty, which at least conceptually in this paper flows from the analogies with genomics and combinations of perspectives from the domain knowledge; go beyond mere theorising to develop value-adding models, frameworks, checklists, and prototype products and services, which are continually tested and refined in real-life settings as depicted in the Oselux Global Economics programmes; and importantly pay attention to the pedagogical merits of the research as explained above. This is the first time that these considerations are explained this way in multidisciplinary research across mathematical sciences, finance and economics.

\section{Acknowledgements}

We are grateful to Nigerian and Libyan government sponsorships of the $\mathrm{PhD}$ research programmes on SSMCD, initially at Sheffield Hallam University, UK; the ICRED and colleagues in ICRED partner universities and financial services organisations for continuing support in this line of work; and anonymous reviewers of this paper for helpful comments that improved its contributions to knowledge.

\section{Conflicts of Interest}

The authors declare no conflicts of interest regarding the publication of this paper.

\section{References}

[1] Ezepue, P.O. and Solarin, A.R.T. (2012) The Meta-Heuristics of Global Financial Risk Management in the Eyes of the Credit Squeeze: Any Lessons for Modelling Emerging Financial Markets? Part I: Key Issues on the Causes and Research Implications of the Credit Squeeze. AFRIHERO Research Report, ARR/Business and Finance/2012/05a. Part II: Discussions with Applications to Some Topics in Investment and Financial Risk Management. AFRIHERO Research Report, ARR/Business and Finance/2012/05b. Part III: A Rejoinder to Professor Soludo's Inaugural Lecture on the Topic "Financial Globalization and Domestic Monetary Policy: Whither the Economics for the 21st Century? AFRIHERO Research Report, ARR/Business and Finance/2012/05c.

[2] Ezepue, P.O. and Omar, M.A.T. (2012) Weak-Form Market Efficiency of the Nigerian Stock Market in the Context of Financial Reforms and Global Financial Crisis. 
Journal of African Business, 13, 209-220.

https://doi.org/10.1080/15228916.2012.727750

[3] Ezepue, P.O. (2018) A Masterclass on Stochastic Modelling in Finance and Economics with a Focus on Current and Emerging Research Directions. Invited Key Note Paper for the May 2017 International Conference on Contemporary Mathematics in the Real World. Transactions of the Nigerian Association of Mathematical Physics, 6, 308-334.

[4] Dalio, R. (2017) Life and Work Principles. Simon \& Schuster.

[5] Urama, T.C. (2018) Stochastic Calculus and Derivatives Pricing in the Nigerian Stock Market. Unpublished PhD Thesis, Sheffield Hallam University, UK.

[6] Raheem, M.A. and Ezepue, P.O. (2018) Some Stylized Facts of Short-Term Stock Prices of Selected Nigerian Banks. Open Journal of Statistics, 8, 94-133. https://doi.org/10.4236/ojs.2018.81008

[7] Urama, T.C. and Ezepue, P.O. (2018) Stochastic Ito-Calculus and Numerical Approximations for Asset Price Forecasting in the Nigerian Stock Market. Journal of Mathematical Finance, 8, 640-667. https://doi.org/10.4236/jmf.2018.84041

[8] Mervyn, K. (2016) The End of Alchemy: Money, Banking and the Future of the Global Economy. Little, Brown.

[9] Ruchir, S. (2016) The Rise and Fall of Nations: Ten Rules of Change in the PostCrisis World.

[10] Ray, D. (2018) The End of Alchemy: Money, Banking and the Future of the Global Economy. Little, Brown. Principles for Navigating Big Debt Crises. Bridgewater Press, Bridgewater.

[11] Ezepue, P.O. and Omar, M.T. (2016) Stochastic Models and Stock Market Characterisation of the Nigerian Stock Market. In: Ezepue, P.O. and Ekhaguere, G.O.S., Eds., 408-427.

[12] Ezepue, P.O. and Ekhaguere, G.O.S. (2016) Proceedings of the International Symposium on Mathematical and Statistical Finance, 1-3 September 2015, Mathematics and Statistics Complex, University of Ibadan, Oyo State, Nigeria. Publications of the SIMFIM 3E-ICMCS Research Consortium.

[13] Aro-Gordon, S. and Chandrashekhar, U. (2016) Impact of Contemporary Technological Tools on Financial Mathematics and Financial Management Services.

[14] Alan, G. (2008) The Age of Turbulence with a Chapter on the Current Credit Crisis. Penguin.

[15] Tetlock, P. and Gardner, D. (2016) Super-Forecasting: The Art \& Science of Prediction.

[16] Nate, S. (2012) The Signal and the Noise: The Art and Science of Prediction. Allen Lane, London.

[17] Berkin, A.L. and Swedroe, L.E. (2016) Your Complete Guide to Factor-Based Investing: The Way Smart Money Invests Today. BAM Alliance Press, St. Louis.

[18] Daniel, P. and Corey, W. (2017) University of Berkshire Hathaway: 30 Years of Lessons from Warren Buffett \& Charlie Munger at the Annual General Meeting. Pecaut and Company, Sioux City.

[19] Urama, T.C., Ezepue, P.O. and Nnanwa, P.C. (2017) Analysis of Cross-Correlations in Emerging Markets Using Random Matrix Theory. Journal of Mathematical Finance, 7, 291-317. http://www.scirp.org/journal/jmf https://doi.org/10.4236/jmf.2017.72015

[20] Urama, T.C., Ezepue, P.O. and Nnanwa, P.C. (2017) Application of Random Matrix 
Theory in Estimating Realistic Implied Correlation Matrix from Option Prices. Proceedings of 6th Annual International Conference on Computational Mathematics, Computational Geometry \& Statistics, (CMCGS) and 5th annual International Conference on Operations Research and Statistics (ORS), Singapore, Global Science and Technology Forum.

[21] Pafka, S. and Kondor, I. (2004) Estimated Correlation Matrices and Portfolio Optimization. Physica A, 343, 623-634. https://doi.org/10.1016/j.physa.2004.05.079

[22] Numpacharoen, K. (2013) Weighted Average Correlation Matrices Method for Correlation Stress Testing and Sensitivity Analysis. The Journal of Derivatives, 21, 67-74. https://doi.org/10.3905/jod.2013.21.2.067

[23] Sensoy, A., Yuksel, S. and Erturk, M. (2013) Analysis of Cross-Correlations between Financial Markets after the 2008 Crisis. Physica A, 392, 5027-5045. https://doi.org/10.1016/j.physa.2013.06.046

[24] Mantegna, R.N. (1999) Hierarchical Structure in Financial Markets. The European Physical Journal B, 11, 193-197. https://doi.org/10.1007/s100510050929

[25] Laurent Laloux, P., Cizeau, J. and Bouchaud, M.P. (1999) Noise Dressing of Financial Correlation Matrices. Physical Review Letters, 83, 1467-1470. https://doi.org/10.1103/PhysRevLett.83.1467

[26] Plerou, V., Gopikrishnan, P., Rosenow, B., Amaral, L.A.N. and Stanley, H.E. (1999) Universal and Non-Universal Properties of Cross-Correlations in Financial Time Series. Physical Review Letters, 83, 1471-1474. https://doi.org/10.1103/PhysRevLett.83.1471

[27] Markowitz, H. (1952) Portfolio Selection. Journal of Finance, 2, 77-91.

[28] Wang, G., Xie, C., Chen, S., Yang, J. and Yang, M. (2013) Random Matrix Theory Analysis of Cross-Correlations in the US Stock Market: Evidence from Pearson's Correlation Coefficient and Detrended Cross-Correlation Coefficient. Physica A, 392, 3715-3730. https://doi.org/10.1016/j.physa.2013.04.027

[29] Black, F. and Scholes, M. (1973) The Pricing of Options Corporate Liabilities. Journal of Political Economy, 81, 637-654. https://doi.org/10.1086/260062

[30] Buss, A. and Vilkov, G. (2012) Measuring Equity Risk with Option-Implied Correlations. The Review of Financial Studies, 25, 3113-3140. https://doi.org/10.1093/rfs/hhs087

[31] Pollet, J.M. and Wilson, M. (2010) Average Correlation and Stock Market Returns. Journal of Financial Economics, 96, 364-380. https://doi.org/10.1016/j.jfineco.2010.02.011

[32] Mayhew, S. (1995) Implied Volatility. Financial Analysts Journal, 51, 8-20. https://doi.org/10.2469/faj.v51.n4.1916

[33] Edelman, A. (1988) Eigenvalues and Condition Numbers of Random Matrices. SIAM Journal on Matrix Analysis and Applications, 9, 543-560. https://doi.org/10.1137/0609045

[34] Rosenow, B., Gopkrishnan, P., Plerou, V. and Eugene Stanley, H. (2002) Random Magnets and Correlations of Stock Price Fluctuations. Physica A, 314, 762-767. https://doi.org/10.1016/S0378-4371(02)01049-X

[35] Cukur, S., Eryigit, M. and Eryigit, R. (2007) Cross-Correlation in an Emerging Market Financial Data. Physica A, 376, 555-564. https://doi.org/10.1016/j.physa.2006.10.074

[36] Junior, L. and Franca, I. (2012) Correlation of Financial Markets in Times of Crisis. Physica A, 391, 187-208. https://doi.org/10.1016/j.physa.2011.07.023 
[37] Sharma, C. and Banerjee, K. (2015) A Study of Correlations in the Stock Market. Physica A, 432, 321-330. https://doi.org/10.1016/j.physa.2015.03.061

[38] Wilcox, D. and Gebbie, T. (2007) An Analysis of Cross-Correlations in an Emerging Market. Physica A, 375, 584-598. https://doi.org/10.1016/j.physa.2006.10.030

[39] Kim, M., Lee, S., Hwang, D., Kim, S. and Ko, I. (2010) Dynamics of Implied Volatility Surfaces from Random Matrix Theory. Physica A, 389, 2762-2769. https://doi.org/10.1016/j.physa.2010.02.042

[40] Pafka, S. and Kondor, I. (2003) Noisy Covariance Matrices and Portfolio Optimization 2. Physica $A, 319,487-494$. https://doi.org/10.1016/S0378-4371(02)01499-1

[41] Galluccio, S., Bouchaud, J. and Potters, M. (1998) Rational Decisions, Random Matrices and Spin Glasses. Physica A, 259, 449-456. https://doi.org/10.1016/S0378-4371(98)00332-X

[42] Colon, T., Ruskin, H.J. and Crane, M. (2007) Random Matrix Theory and Fund of Funds Portfolio Optimization. Physica A, 382, 565-576. https://doi.org/10.1016/j.physa.2007.04.039

[43] Laloux, L., Cizeau, P., Potters, M. and Bouchaud, J. (2000) Random Matrix Theory and Financial Correlations. International Journal of Theoretical and Applied Finance, 3, 391-397. https://doi.org/10.1142/S0219024900000255

[44] Gopikrishnan, P., Rosenow, B., Plerou, V. and Stanley, E. (2001) Quantifying and Interpreting Collective Behaviour in Financial Markets. Physical Review E, 64, Article ID: 035106. https://doi.org/10.1103/PhysRevE.64.035106

[45] Plerou, V., Gopikrishnan, P., Rosenow, B., Amaral, L.A.N. and Stanley, H.E. (2000) A Random Matrix Theory Approach to Financial Cross-Correlations. Physica $A$, 287, 374-382. https://doi.org/10.1016/S0378-4371(00)00376-9

[46] Sharifi, S., Crane, M., Shamaie, A. and Ruskin, H. (2004) Random Matrix Theory for Portfolio Optimisation: A Stability Approach. Physica A, 335, 629-643. https://doi.org/10.1016/j.physa.2003.12.016

[47] Markowitz, H. (1952) Portfolio Selection. Journal of Finance, 2, 77-91.

[48] Engle, R. and Figlewski, S. (2014) Modeling the Dynamics of Correlation among Implied Volatilities. Review of Finance, 19, 991-1018. https://doi.org/10.1093/rof/rfu024

[49] Black, F. and Scholes, M. (1973) The Pricing of Options Corporate Liabilities. Journal of Political Economy, 81, 637-654. https://doi.org/10.1086/260062

[50] Plerou, V., Gopikrishnan, P., Rosenow, B., Amaral, L.A.N. and Stanley, H.E. (2001) Collective Behaviour of Stock Price Movements: A Random Matrix Theory Approach. Physica A, 299, 175-180. https://doi.org/10.1016/S0378-4371(01)00293-X

[51] Dyson, F.J. (1971) Distribution of Eigenvalues for a Class of Real Symmetric Matrices. Revista Mexicana de Física, 20, 231-237.

[52] Guhr, T., Muller, A. and Weidenmuller, H. (1998) Random Matrix Theories in Quantum Physics: Common Concepts. Physics Reports, 299, 189-425. https://doi.org/10.1016/S0370-1573(97)00088-4

[53] Utsugi, A., Ino, K. and Oshikawa, M. (2004) Random Matrix Theory Analysis of Cross-Correlations in Financial Markets. Physical Review E, 70, Article ID: 026110. https://doi.org/10.1103/PhysRevE.70.026110

[54] Numpacharoen, K. and Numpacharoen, N. (2013) Estimating Realistic Implied Correlation Matrix from Option Prices. Journal of Mathematical Finance, 3, 401-406. 
https://doi.org/10.4236/jmf.2013.34041

[55] Donald, P. (1978) Chiras and Steven Manaster, The Information Content of Option Prices and a Test of Market Efficiency. Journal of Financial Economics, 6, 213-234. https://doi.org/10.1016/0304-405X(78)90030-2

[56] Kim, G. and Markowitz, H.M. (1989) Investment Rules, Margin and Market Volatility. The Journal of Portfolio Management, 16, 45-52. https://doi.org/10.3905/jpm.1989.409233

[57] Bensman, M. (1997) Hedging Multiple Currency Exposures: The Easy Way Derivatives Strategy.

[58] Raheem, M.A. (2018) Stochastic-Time Series Modelling for the Banking Sector of the Nigerian Stock Market. PhD Thesis, Sheffield Hallam University, Sheffield, Nigeria.

[59] Raheem, M.A. and Ezepue, P.O. (2017) Stock Volatility in the Eyes of Turbulence: Evidence from Nigerian Banks. Mathematical Finance Letters, 2017, 2051-2929.

[60] Nnanwa, C.P. (2018) Mathematical Analysis in Investment Theory: Applications to the Nigerian Stock Market. PhD Thesis, Sheffield Hallam University, Sheffield, UK.

[61] Markowitz, H. (1959) Portfolio Selection: Efficient Diversification of Investment. John Wiley and Sons, New York.

[62] Nigel, M. (2018) No-Deal Brexit "Would Plunge [UK] Economy into Meltdown". News Section of the UK Newspaper, 8-9.

[63] Rhys, B. and Tang, D. (2018) Scientist Claims First Gene-Edited Babies. The Times UK, 11.

[64] Caleb, H. (2018) Brain Scan. In Technology Quarterly. The Future of Agriculture. The Economist, June $11^{\text {th }}, 2016$, p. 7.

[65] Voit, J. (2001) The Statistical Mechanics of Financial Markets. Springer, Berlin. https://doi.org/10.1007/978-3-662-04423-0

[66] Ezepue, P.O. (2015) Grasping the Basics and Stylistics of Critical Literature Reviews and Academic Writing. AFRIHERO Research Report: ARR/Statistical Modelling/ Global Tuition and Research Support Services. 